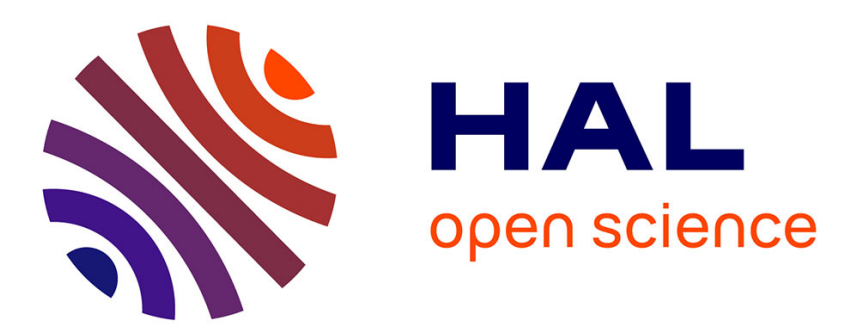

\title{
First-principles nickel database: Energetics of impurities and defects
}

\author{
Damien Connétable, Éric Andrieu, Daniel Monceau
}

\section{To cite this version:}

Damien Connétable, Éric Andrieu, Daniel Monceau. First-principles nickel database: Energetics of impurities and defects. Computational Materials Science, 2015, 101, pp.77-87. 10.1016/j.commatsci.2015.01.017 . hal-01470306

\section{HAL Id: hal-01470306 https://hal.science/hal-01470306}

Submitted on 17 Feb 2017

HAL is a multi-disciplinary open access archive for the deposit and dissemination of scientific research documents, whether they are published or not. The documents may come from teaching and research institutions in France or abroad, or from public or private research centers.
L'archive ouverte pluridisciplinaire HAL, est destinée au dépôt et à la diffusion de documents scientifiques de niveau recherche, publiés ou non, émanant des établissements d'enseignement et de recherche français ou étrangers, des laboratoires publics ou privés. 


\section{OATAO \\ Open Archive Toulouse Archive Ouverte}

\section{Open Archive TOULOUSE Archive Ouverte (OATAO)}

OATAO is an open access repository that collects the work of Toulouse researchers and makes it freely available over the web where possible.

This is an author-deposited version published in : http://oatao.univ-toulouse.fr/ Eprints ID : 16697

To link to this article : DOI:10.1016/j.commatsci.2015.01.017

URL : http://dx.doi.org/10.1016/j.commatsci.2015.01.017

To cite this version : Connétable, Damien and Andrieu, Éric and Monceau, Daniel First-principles nickel database: Energetics of impurities and defects. (2015) Computational Materials Science, vol. 101. pp. 77-87. ISSN 0927-0256

Any correspondence concerning this service should be sent to the repository administrator: staff-oatao@,listes-diff.inp-toulouse.fr 


\title{
First-principles nickel database: Energetics of impurities and defects
}

\author{
Damien Connétable* ${ }^{*}$, Éric Andrieu, Daniel Monceau

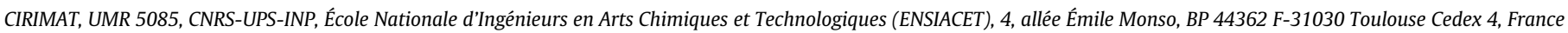

\begin{abstract}
A B S T R A C T
A database of thermodynamic solubility energies of impurities and defects in solid solution in fcc-nickel is reported using an extensive series of first-principles calculations, based on density functional theory (DFT). The solubility and insertion energies of solute elements, intrinsic (vacancies) and self-interstitial defects (dumbbells) are computed. The DFT energies of the main elements of the periodic table are compared to the experimental and theoretical literature, and the influence of the solute atoms on the network is discussed. We obtained that for most of the species the substitution sites are preferred to the interstitial sites (including $\mathrm{He}, \mathrm{Li}, \mathrm{F}, \mathrm{P}, \mathrm{S}$ and $\mathrm{Cl}$ atoms), except in the case of the five elements, $\mathrm{B}, \mathrm{C}, \mathrm{N}, \mathrm{O}$ and $\mathrm{H}$, which are observed preferentially in interstitial octahedral sites. The migration mechanisms are presented for these interstitial elements and for the particular case of $\mathrm{He}$, including the vibrational contribution.
\end{abstract}

Keywords:

First-principles calculations

Defect

Nickel

Solubility

Interstitials

Migration

Density functional theory

\section{Introduction}

Due to their relevance for a wide variety of phenomena arising in materials processing, extensive efforts are devoted to the development of databases for solubility energies in multi-component alloys, as illustrated by the strong development of the thermodynamics databases. Ni-based alloys are commonly used as refractory structural materials due to their mechanical properties. This specific properties are partly attributed to the elements dissolved in the fcc Ni-matrix, which contribute to the mechanical properties by different strengthening mechanisms $[1,2]$. The solid-solution strengthening due to lattice distortion and the interference of the alloying in the lattice periodicity is the first mechanism [1]. In Ni-based alloys, W, V, Mo, Co, Re, $\mathrm{Cr}$ and $\mathrm{Al}$ are involved in the solid-solute strengthening. When used at high temperatures, the dissolution and diffusion of $\mathrm{O}, \mathrm{N}, \mathrm{C}$, and $\mathrm{S}$ are also involved with high temperature corrosion, internal oxidation, nitration or carburation. These elements can also cause the embrittlement of the alloys. Together with boron and hydrogen, they can be found to segregate at grain boundaries and inter-phases and interact strongly with point-defects $[3,4]$. To protect Ni-based alloys from high temperature oxidation, it is necessary to alloy them with $\mathrm{Al}$, $\mathrm{Cr}$ or Si to form an external protective oxide layer of $\mathrm{Al}_{2} \mathrm{O}_{3}, \mathrm{Cr}_{2} \mathrm{O}_{3}$ or $\mathrm{SiO}_{2}$. To do so, the alloy must accept a sufficient quantity of atoms ( $\mathrm{Al}, \mathrm{Cr}$ or $\mathrm{Si}$ ) and must have a limited diffusivity of oxygen,

\footnotetext{
* Corresponding author.

E-mail address: damien.connetable@ensiacet.fr (D. Connétable).
}

i.e., a limited solubility and diffusion coefficient for oxygen [5]. When adding elements such as $\mathrm{Al}, \mathrm{Ti}, \mathrm{Ta}, \mathrm{Nb}$, and $\mathrm{C}$, their solubility and diffusion also control the nucleation and growth kinetics of precipitates (e.g., $\gamma^{\prime}-\mathrm{Ni}_{3} \mathrm{Al}$, or $\delta$ or $\gamma^{\prime \prime}-\mathrm{Ni}_{3} \mathrm{Nb}$ and $\mathrm{Cr}$-carbides), that control the mechanical properties of Ni-based alloys.

However, few data are available in the experimental and theoretical literature for elements in solid solution. The strength of the numerical simulations (DFT) allows a systematic study to obtain experimental and theoretical data on the solubility properties in fcc-nickel. Janotti et al. [6] studied the solute diffusion for different transition metals ( $\mathrm{Ti}, \mathrm{V}, \mathrm{Cr}, \mathrm{Mn}, \mathrm{Fe}, \mathrm{Co}, \mathrm{Ni}$ and $\mathrm{Cu}$ ) without giving the solubility energies. They showed that, according to the interactions between solute and vacancy, larger atoms can move faster than lighter atoms. Yamaguchi [7] studied the segregation for a large number of elements in symmetric grain boundaries $\Sigma_{5}-\mathrm{Ni}$ and free surfaces. Some species have already been studied in detail: Nb [8], C [9], O [10,11], H [12,3], S [13,14] and He [15].

The aim of this work is to provide information on all impurities and solutes in nickel. We present a complete database of solubility and insertion energies for most species in solid solution in nickel using first-principles calculations. With the state-of-art techniques (highly converged calculations on large super-cells) we present an accurate reference database. For interstitial elements, we also report migration mechanisms.

Section 2 is devoted to numerical approximations. The results for each element are presented and discussed in Section 3. In Section 4 , the migration mechanisms of interstitial elements are discussed. 
Table 1

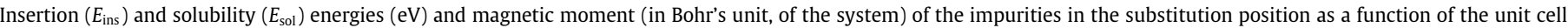

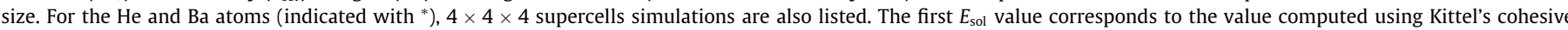
energy.

\begin{tabular}{|c|c|c|c|c|c|c|c|c|c|c|c|}
\hline & \multicolumn{2}{|c|}{$2 \times 2 \times 2$} & \multicolumn{3}{|l|}{$3 \times 3 \times 3$} & & \multicolumn{2}{|c|}{$2 \times 2 \times 2$} & \multicolumn{3}{|l|}{$3 \times 3 \times 3$} \\
\hline & $E_{\text {ins }}$ & $\mu_{B}$ & $E_{\text {ins }}$ & $E_{\text {sol }}$ & $\mu_{B}$ & & $E_{\text {ins }}$ & $\mu_{B}$ & $E_{\text {ins }}$ & $E_{\text {sol }}$ & $\mu_{B}$ \\
\hline $\mathrm{H}$ & -0.168 & 18.5 & - & & - & $\mathrm{Zr}$ & -7.308 & 15.6 & -7.376 & $-1.126 /-0.946$ & 61.5 \\
\hline $\mathrm{He}$ & 3.234 & 19.0 & $3.212 / 3.205^{*}$ & $0.000 / 3.212$ & 64.9 & $\mathrm{Nb}$ & -7.739 & 14.9 & -7.735 & $-0.165 /-0.704$ & 60.7 \\
\hline $\mathrm{Li}$ & -1.690 & 18.3 & -1.732 & $-0.102 /-0.112$ & 64.3 & Mo & -6.477 & 14.9 & -6.411 & $0.409 /-0.027$ & 60.3 \\
\hline $\mathrm{Be}$ & -4.333 & 17.6 & -4.384 & $-1.064 /-0.695$ & 63.7 & Tc & -6.850 & 16.6 & -6.727 & $0.123 / 0.354$ & 63.0 \\
\hline B & -5.668 & 17.2 & -5.704 & $0.106 / 0.727$ & 63.3 & $\mathrm{Ru}$ & -6.454 & 19.2 & -6.442 & $0.298 / 0.445$ & 66.3 \\
\hline C & -4.290 & 17.8 & - & & - & $\mathrm{Rh}$ & -5.733 & 19.9 & -5.729 & $0.021 / 0.097$ & 66.0 \\
\hline $\mathrm{N}$ & -1.642 & 19.4 & - & & - & $\mathrm{Pd}$ & -3.473 & 19.3 & -3.463 & $0.427 / 0.252$ & 65.3 \\
\hline $\mathrm{O}$ & -1.773 & 19.5 & - & & - & $\mathrm{Ag}$ & -1.462 & 18.5 & -1.432 & $1.518 / 1.115$ & 64.6 \\
\hline $\mathrm{F}$ & -0.869 & 19.3 & -0.872 & $-0.032 / 0.380$ & 65.4 & $\mathrm{Cd}$ & 0.030 & 17.9 & 0.047 & $1.207 / 0.817$ & 63.9 \\
\hline $\mathrm{Ne}$ & 4.389 & 19.0 & 4.367 & $4.387 / 4.413$ & 64.9 & In & -2.200 & 17.2 & -2.192 & $0.328 / 0.173$ & 63.2 \\
\hline $\mathrm{Na}$ & 0.942 & 18.4 & 0.904 & $2.017 / 2.002$ & 64.3 & Sn & -3.491 & 16.6 & -3.471 & $-0.331 /-0.211$ & 62.7 \\
\hline $\mathrm{Mg}$ & -1.739 & 17.6 & -1.781 & $-0.271 /-0.297$ & 63.6 & $\mathrm{Sb}$ & -3.023 & 16.2 & -2.990 & $-0.240 /-0.173$ & 62.4 \\
\hline $\mathrm{Al}$ & -5.025 & 16.9 & -5.069 & $-1.679 /-1.636$ & 63.0 & $\mathrm{Te}$ & -2.137 & 16.1 & -2.100 & $0.090 / 0.421$ & 62.5 \\
\hline $\mathrm{Si}$ & -6.207 & 16.4 & -6.231 & $-1.601 /-1.577$ & 62.6 & I & 1.044 & 16.6 & 1.089 & $2.199 / 2.258$ & 62.8 \\
\hline $\mathrm{P}$ & -4.576 & 16.6 & -4.602 & $-1.172 /-1.140$ & 62.9 & $\mathrm{Xe}$ & 7.457 & 17.2 & 7.585 & $7.745 / 7.639$ & 63.5 \\
\hline S & -2.783 & 17.8 & -2.827 & $-0.627 /-0.242$ & 63.9 & Cs & 5.699 & 16.9 & 5.836 & $6.640 / 6.541$ & 63.2 \\
\hline $\mathrm{Cl}$ & 0.723 & 18.4 & 0.716 & $2.116 / 2.214$ & 64.7 & $\mathrm{Ba}$ & 2.384 & 16.5 & $2.513 / 2.604^{*}$ & $4.413 / 4.406$ & 62.8 \\
\hline $\mathrm{Ar}$ & 6.685 & 18.3 & 6.656 & $6.736 / 6.656$ & 64.7 & $\mathrm{Ce}$ & -4.621 & 14.6 & -4.560 & $-0.240 /-0.195$ & 60.7 \\
\hline K & 4.005 & 18.2 & 3.979 & $4.913 / 4.850$ & 64.0 & $\operatorname{Pr}$ & -3.074 & 16.2 & -2.959 & $0.741 / 1.505$ & 61.8 \\
\hline $\mathrm{Ca}$ & -0.344 & 17.5 & -0.395 & $1.445 / 1.502$ & 63.4 & Nd & -3.193 & 16.2 & -3.109 & $0.291 / 1.214$ & 61.9 \\
\hline Sc & -5.827 & 16.5 & -5.901 & $-2.001 /-1.150$ & 62.5 & $\mathrm{Pm}$ & -3.793 & 16.3 & -3.723 & $-1-3.723$ & 61.9 \\
\hline $\mathrm{Ti}$ & -7.071 & 15.6 & -7.119 & $-2.269 /-1.526$ & 61.6 & $\mathrm{Sm}$ & -4.040 & 16.3 & -3.993 & $-1.853 / 0.800$ & 62.0 \\
\hline V & -6.277 & 15.1 & -6.273 & $-0.963 /-0.821$ & 60.8 & $\mathrm{Eu}$ & -1.237 & 16.9 & -1.282 & $0.578 / 0.588$ & 62.8 \\
\hline $\mathrm{Cr}$ & -4.100 & 14.3 & -3.966 & $0.134 / 0.238$ & 64.6 & $\mathrm{Gd}$ & -3.977 & 16.4 & -3.947 & $0.193 / 0.365$ & 62.0 \\
\hline Mn & -4.320 & 21.8 & -4.361 & $-1.441 /-0.245$ & 68.0 & $\mathrm{~Tb}$ & -4.141 & 16.4 & -4.130 & $-0.080 / 0.199$ & 62.1 \\
\hline $\mathrm{Fe}$ & -5.360 & 21.3 & -5.367 & $-1.087 /-0.320$ & 67.5 & Dy & -4.284 & 16.4 & -4.280 & $-1.240 / 0.054$ & 62.1 \\
\hline Co & -5.480 & 20.5 & -5.490 & $-1.100 /-0.056$ & 67.8 & Ho & -4.322 & 16.4 & -4.324 & $-1.184 /-0.070$ & 62.0 \\
\hline $\mathrm{Ni}$ & -4.913 & 19.4 & -4.913 & $0.000 / 0.004$ & 67.3 & $\mathrm{Er}$ & -4.425 & 16.5 & -4.436 & $-1.146 /-0.203$ & 62.2 \\
\hline $\mathrm{Cu}$ & -3.346 & 18.4 & -3.372 & $0.118 / 0.122$ & 64.5 & $\mathrm{Yb}$ & -1.306 & 17.2 & -1.372 & $0.228 / 0.098$ & 63.0 \\
\hline $\mathrm{Zn}$ & -1.554 & 17.7 & -1.611 & $-0.261 /-0.495$ & 63.8 & $\mathrm{Hf}$ & -7.802 & 15.6 & -7.860 & $-1.420 /-1.360$ & 61.6 \\
\hline $\mathrm{Ga}$ & -3.692 & 17.1 & -3.721 & $-0.911 /-1.033$ & 63.1 & Ta & -9.746 & 14.8 & -9.751 & $-1.651 /-1.071$ & 60.7 \\
\hline $\mathrm{Ge}$ & -4.693 & 16.6 & -4.722 & $-0.872 /-0.886$ & 62.8 & W & -8.700 & 14.4 & -8.661 & $0.239 /-0.216$ & 60.0 \\
\hline As & -3.611 & 16.6 & -3.638 & $-0.678 /-0.659$ & 62.9 & Os & -8.084 & 17.6 & -8.015 & $0.155 / 0.524$ & 64.9 \\
\hline Se & -2.353 & 17.2 & -2.388 & $0.072 / 0.351$ & 63.4 & $\mathrm{Ir}$ & -7.407 & 19.4 & -7.401 & $-0.461 / 0.021$ & 65.9 \\
\hline $\mathrm{Br}$ & 1.041 & 18.0 & 1.056 & $2.276 / 2.357$ & 64.2 & $\mathrm{Pt}$ & -5.713 & 19.3 & -5.706 & $0.134 /-0.175$ & 65.3 \\
\hline $\mathrm{Kr}$ & 7.197 & 17.9 & 7.232 & $7.348 / 7.281$ & 64.3 & $\mathrm{Au}$ & -2.461 & 18.6 & -2.404 & $1.406 / 0.639$ & 64.6 \\
\hline $\mathrm{Rb}$ & 5.213 & 17.7 & 5.273 & $6.125 / 6.045$ & 64.1 & $\mathrm{Hg}$ & 0.994 & 18.0 & 1.037 & $1.707 / 1.233$ & 64.0 \\
\hline $\mathrm{Sr}$ & 1.343 & 17.3 & 1.348 & $3.068 / 2.956$ & 63.2 & $\mathrm{~Pb}$ & -1.777 & 16.8 & -1.715 & $0.315 / 1.299$ & 62.9 \\
\hline Y & -4.720 & 16.5 & -4.723 & $-0.353 / 0.270$ & 62.4 & $\mathrm{Bi}$ & -1.425 & 16.5 & -1.353 & $0.827 / 1.139$ & 62.7 \\
\hline
\end{tabular}

\section{Computational details}

The calculations were performed within the density functional theory (DFT) formalism, using the Vienna $a b$ initio simulation program (VASP) [16-19] using the projector-augmented-wave (PAW) pseudopotentials [20]. The spin-polarized version of the PerdewWang (PW91 [21]) generalized gradient approximation (GGA) was used for the exchange and correlation functional. The cut-off energy was maintained at $600 \mathrm{eV}$ for all elements, and the Brillouin zones were sampled using $24 \times 24 \times 24 k$-mesh grids for the fcc unit cell with four atoms, and a band-folding approach [22] for supercells. These parameters provide an excellent convergence for the energy values ( $<1 \mathrm{meV}$ per atom). The lattice parameters and the ions were allowed to relax. Within these criteria, the ground state properties of fcc nickel (the lattice parameter, the cohesive energy and the magnetic moment were equal to $3.52 \AA$, $4.89 \mathrm{eV} /$ atom and $0.62 \mu_{B}$, respectively) agreeing with previous DFT calculations [8] and the experimental values [23]. We employed supercells to model the defects and to study the impurities. To determine the preferred site, we used $2 \times 2 \times 2$ cubic supercells ( 32 atoms). The converged energies were then calculated on larger supercells ( $3 \times 3 \times 3$, i.e., $108 \mathrm{Ni}$ atoms). However, to limit the number of simulations, when the substitutional site (or the interstitial site) was the more stable configuration, the energy of the interstitial (substitutional) sites was only evaluated on the $2 \times 2 \times 2$ supercells. The atomic energies of the solutes $X$ (labeled $\mu_{\mathrm{at}}^{\mathrm{o}}[\mathrm{X}]$ ) were calculated on large non-cubic supercells $\left(10 \times 11 \times 12 \AA^{3}\right)$. The energies of the reference states were also computed. In most of cases, the reference states were given by Kittel [23], i.e., either a hexagonal close-packed structure (hcp, with two atoms per unit-cell), a cubic structure (fcc, bcc, sc or diamond, with one or two atoms in the primitive cell) or a molecule (diatomic). However, for As, [24] B, [25] Be, [26] Ga, [27] Mn, [28] P, [29] Pr, [30] Sb, [31] Se, [32] Sm [33] and Te, [34] the reference states have more complex structures. Fine Monkhorst-Pack grids [35] were adopted to calculate the ground-state energies ( $\Gamma$-centered grids, with more than 14,000 $k$-points per atom to sample the reciprocal Brillouin zone). We show in Tables B.9 and B.10 the results for the reference states: the lattice parameters, the cohesive energies and the magnetic moment, to verify that our results for the reference states agree satisfactorily with the experimental results.

\section{Interstitial or substitutional site}

In the face-centered cubic structures, there are three main sites for the added atoms: (i) the two interstitial sites, i.e., the octahedral and the tetrahedral site (labeled in the following as $(\mathrm{O})$ and $(\mathrm{T})$, respectively) and (ii) the substitutional site (i.e., replacing a $\mathrm{Ni}$ 
Table 2

Insertion $\left(E_{\text {ins }}\right)$ energies $(\mathrm{eV})$ of impurities in the octahedral and tetrahedral sites computed on $2 \times 2 \times 2$ supercells. Only substituted elements are listed.

\begin{tabular}{|c|c|c|c|c|c|c|c|c|c|}
\hline & $E_{\text {ins }}$ & $\mu_{B}$ & $E_{\text {ins }}$ & $\mu_{B}$ & & $E_{\text {ins }}$ & $\mu_{B}$ & $E_{\text {ins }}$ & $\mu_{B}$ \\
\hline & \multicolumn{2}{|l|}{ octa } & \multicolumn{3}{|l|}{ tetra } & \multicolumn{2}{|l|}{ octa } & \multicolumn{2}{|l|}{ tetra } \\
\hline $\mathrm{Li}$ & 1.190 & 18.7 & 2.117 & 18.6 & $\mathrm{Ru}$ & -1.955 & 18.2 & -1.031 & 19.1 \\
\hline $\mathrm{Be}$ & -2.548 & 17.9 & -1.019 & 17.9 & $\mathrm{Rh}$ & -1.087 & 20.1 & -0.064 & 20.3 \\
\hline $\mathrm{F}$ & 0.317 & 20.0 & 0.058 & 20.1 & Pd & 1.097 & 19.8 & 2.461 & 20.0 \\
\hline $\mathrm{Ne}$ & 7.520 & 19.4 & 7.811 & 19.6 & $\mathrm{Ag}$ & 3.135 & 19.3 & 4.846 & 19.2 \\
\hline $\mathrm{Na}$ & 5.026 & 18.8 & 5.908 & 18.8 & $\mathrm{Cd}$ & 4.690 & 18.5 & 6.483 & 18.4 \\
\hline $\mathrm{Mg}$ & 2.535 & 18.1 & 3.663 & 18.1 & In & 2.399 & 17.7 & 4.211 & 17.7 \\
\hline $\mathrm{Al}$ & -1.155 & 17.3 & 0.168 & 17.4 & Sn & 0.980 & 17.2 & 2.826 & 17.2 \\
\hline $\mathrm{Si}$ & -3.382 & 16.8 & -1.830 & 16.8 & $\mathrm{Sb}$ & 1.174 & 16.9 & 2.998 & 16.8 \\
\hline $\mathrm{P}$ & -3.081 & 16.5 & -1.443 & 16.6 & $\mathrm{Te}$ & 1.694 & 17.1 & 3.499 & 16.9 \\
\hline $\mathrm{Cl}$ & 2.207 & 18.1 & 2.969 & 18.5 & I & 4.463 & 17.5 & 6.215 & 17.6 \\
\hline $\mathrm{Ar}$ & 9.692 & 18.8 & 10.109 & 19.1 & $\mathrm{Xe}$ & 10.912 & 17.6 & 12.756 & 18.4 \\
\hline K & 7.939 & 18.6 & 8.851 & 18.6 & Cs & 9.281 & 17.5 & 11.025 & 18.1 \\
\hline $\mathrm{Ca}$ & 3.839 & 17.8 & 4.660 & 17.9 & $\mathrm{Ba}$ & 6.296 & 17.2 & 8.149 & 17.7 \\
\hline Sc & -1.706 & 17.0 & -0.819 & 17.1 & $\mathrm{Ce}$ & -1.147 & 15.5 & -0.228 & 15.8 \\
\hline $\mathrm{Ti}$ & -3.433 & 16.1 & -2.673 & 16.2 & $\operatorname{Pr}$ & 1.060 & 16.7 & 2.583 & 17.1 \\
\hline V & -2.812 & 15.4 & -2.055 & 15.5 & $\mathrm{Nd}$ & 0.952 & 16.7 & 2.419 & 17.1 \\
\hline $\mathrm{Cr}$ & -0.667 & 15.1 & 0.054 & 14.9 & $\mathrm{Pm}$ & 0.391 & 16.8 & 1.792 & 17.1 \\
\hline Mn & -0.418 & 19.1 & 0.431 & 19.4 & $\mathrm{Sm}$ & 0.169 & 16.8 & 1.521 & 17.1 \\
\hline $\mathrm{Fe}$ & -1.605 & 21.8 & -0.643 & 21.7 & $\mathrm{Eu}$ & 2.684 & 17.4 & 3.590 & 17.5 \\
\hline Co & -1.758 & 21.1 & -0.850 & 21.0 & $\mathrm{Gd}$ & 0.257 & 16.9 & 1.527 & 17.2 \\
\hline $\mathrm{Cu}$ & 0.503 & 19.1 & 1.834 & 19.0 & $\mathrm{~Tb}$ & 0.132 & 16.9 & 1.369 & 17.2 \\
\hline $\mathrm{Zn}$ & 2.297 & 18.2 & 3.786 & 18.2 & Dy & -0.133 & 16.9 & 1.233 & 17.2 \\
\hline $\mathrm{Ga}$ & -0.036 & 17.6 & 1.524 & 17.5 & Ho & 0.005 & 16.9 & 1.215 & 17.2 \\
\hline $\mathrm{Ge}$ & -1.439 & 17.1 & 0.168 & 17.1 & $\mathrm{Er}$ & -0.075 & 17.0 & 1.124 & 17.2 \\
\hline As & -0.868 & 16.8 & 0.710 & 16.8 & $\mathrm{Yb}$ & 2.799 & 17.7 & 3.648 & 17.7 \\
\hline Se & 0.010 & 17.3 & 1.458 & 17.2 & $\mathrm{Hf}$ & -3.433 & 16.2 & -2.265 & 16.4 \\
\hline $\mathrm{Br}$ & 3.552 & 17.9 & 4.707 & 18.3 & $\mathrm{Ta}$ & -5.431 & 15.4 & -4.223 & 15.7 \\
\hline $\mathrm{Kr}$ & 10.314 & 18.3 & 11.328 & 18.8 & W & -4.368 & 14.9 & -3.168 & 15.1 \\
\hline $\mathrm{Rb}$ & 9.027 & 18.3 & 10.299 & 18.5 & Os & -3.439 & 16.7 & -2.266 & 17.7 \\
\hline $\mathrm{Sr}$ & 5.584 & 17.8 & 6.901 & 17.9 & $\mathrm{Ir}$ & -2.590 & 19.3 & -1.395 & 19.8 \\
\hline Y & -0.381 & 16.9 & 0.855 & 17.2 & $\mathrm{Pt}$ & -0.930 & 19.7 & 0.533 & 20.0 \\
\hline $\mathrm{Zr}$ & -3.065 & 16.1 & -1.881 & 16.4 & $\mathrm{Au}$ & 2.184 & 19.4 & 4.103 & 19.3 \\
\hline $\mathrm{Nb}$ & -3.576 & 15.4 & -2.470 & 15.7 & $\mathrm{Hg}$ & 5.594 & 18.8 & 7.660 & 18.5 \\
\hline Mo & -2.334 & 15.0 & -1.301 & 15.1 & $\mathrm{~Pb}$ & 2.660 & 17.4 & 4.714 & 17.4 \\
\hline Tc & -2.555 & 15.8 & -1.558 & 15.9 & $\mathrm{Bi}$ & 2.875 & 17.1 & 4.935 & 17.1 \\
\hline
\end{tabular}

atom). In the following, only symmetric configurations were considered for the substitutional configuration, no off-centered positions. To analyze the relative thermodynamic stability of the sites considering that the number of the Ni atoms in the two the configurations is not the same, we used two sets of equations to compute the solubility (and the insertion) energies, labeled $E_{\text {sol }}\left(E_{\text {ins }}\right)$, according to the site studied. The $E_{\text {sol }}[X]$ energy of an $X$ impurity in an interstitial site $((\mathrm{T})$ and $(\mathrm{O}))$ is evaluated using

$E_{\mathrm{sol}}[X]=E_{o}[n \cdot \mathrm{Ni}+\mathrm{X}]-E_{o}[n \cdot \mathrm{Ni}]-\mu_{\mathrm{ref}}^{\mathrm{o}}[X]$

and for the substitutional sites,

$E_{\mathrm{sol}}[X]=E_{o}[(n-1) \cdot \mathrm{Ni}+\mathrm{X}]-E_{o}[n \cdot \mathrm{Ni}]+\mu_{\mathrm{ref}}^{\mathrm{o}}[N i]-\mu_{\mathrm{ref}}^{\mathrm{o}}[X]$

The insertion energy $\left(E_{\text {ins }}\right)$ is computed using the chemical potential of the free atom defined above $\left(\mu_{\mathrm{at}}^{\mathrm{o}}[X]\right)$, while the solubility energy is computed using the chemical potential of the reference state (per atom) of the $X$ species $\left(\mu_{\mathrm{ref}}^{\mathrm{o}}[X]\right)$, listed in Tables B.9 and B.10. The $E_{o}[n . \mathrm{Ni}]$ energy is associated with the energy of the system with $n$ nickel atoms. $E_{o}[(n-1) \cdot \mathrm{Ni}+\mathrm{X}]$ and $E_{o}[n \cdot \mathrm{Ni}+\mathrm{X}]$ are the energies of the system with one solute in the substitutional site and one in the interstitial site, respectively. The difference between the insertion and the solubility energy corresponds to the cohesive energy of the reference state of the $X$ atom. We report the solubility energies calculated using two reference energies: either the experimental cohesive energies (data were taken from Kittel [23]), or the DFT energies of the reference states (those listed in the third columns of Tables B.9 and B.10 in Appendix B).

Tables $1-3$ provide the energies of the substitutional, tetrahedral and octahedral sites for all elements studied, according to the supercell size. The final energies are weakly dependent on the supercell size, so they quickly converge. In some cases (for the $\mathrm{Ba}$ and $\mathrm{He}$ atoms), larger supercells $(4 \times 4 \times 4)$ were employed to check the accuracy of the values. Figs. 1 and 2 show the relative stability (the solubility and the insertion energies, respectively) of the sites by impurity. The $\mathrm{Ni}$ atom was also considered (in the case of the interstitial sites) for comparison. From these data, we can now discuss the interactions between the solute and the matrix (nickel).

\subsection{General trend: the substitutional sites}

For the main species, except for $\mathrm{C}, \mathrm{N}, \mathrm{O}, \mathrm{H}$ and $\mathrm{B}$, see below, the substitutional position is the more stable configuration. In the literature, only three substitutional elements have been reported in detail: the $S$ atom $[13,14]$, which is a poison for transition metals, the $\mathrm{Nb}$ atom [8] which is involved in the hardening of the superalloys

Table 3

Solubility $\left(E_{\text {sol }}\right)$ and insertion $\left(E_{\text {ins }}\right)$ energies $(\mathrm{eV})$ of the tetrahedral and octahedral interstitial positions.

\begin{tabular}{|c|c|c|c|c|c|}
\hline & \multicolumn{2}{|c|}{$2 \times 2 \times 2$} & \multicolumn{3}{|c|}{$3 \times 3 \times 3$} \\
\hline & $E_{\text {ins }}$ & $\mu_{B}$ & $E_{\text {ins }}$ & $E_{\text {sol }}$ & $\mu_{B}$ \\
\hline \multicolumn{6}{|c|}{ octahedral sites } \\
\hline $\mathrm{H}$ & -2.217 & 18.7 & -2.219 & $0.041 / 0.061$ & 64.8 \\
\hline $\mathrm{He}$ & 4.514 & 19.2 & 4.556 & $4.556 / 4.556$ & 65.5 \\
\hline B & -6.480 & 17.1 & -6.397 & $-0.587 / 0.033$ & 63.2 \\
\hline $\mathrm{C}$ & -7.396 & 16.6 & -7.356 & $0.014 / 0.540$ & 62.6 \\
\hline $\mathrm{N}$ & -4.723 & 16.8 & -4.700 & $0.220 / 0.617$ & 62.7 \\
\hline $\mathrm{O}$ & -2.903 & 19.2 & -2.825 & $-0.225 / 0.311$ & 65.4 \\
\hline$S$ & -2.027 & 16.9 & -1.737 & $0.463 / 0.848$ & 62.7 \\
\hline $\mathrm{Ni}$ & -1.194 & 19.9 & -0.810 & $3.630 / 4.107$ & 66.0 \\
\hline \multicolumn{6}{|c|}{ tetrahedral sites } \\
\hline $\mathrm{H}$ & -1.989 & 18.6 & -1.990 & $0.270 / 0.290$ & 64.8 \\
\hline $\mathrm{He}$ & 4.377 & 19.0 & 4.393 & $4.393 / 4.393$ & 65.5 \\
\hline B & -4.596 & 17.2 & -4.614 & $1.660 / 1.817$ & 63.2 \\
\hline $\mathrm{C}$ & -5.746 & 16.7 & -5.710 & $1.660 / 2.186$ & 62.6 \\
\hline $\mathrm{N}$ & -3.729 & 16.7 & -3.655 & $1.265 / 1.662$ & 62.7 \\
\hline $\mathrm{O}$ & -2.704 & 19.1 & -2.661 & $-0.061 / 0.474$ & 65.4 \\
\hline S & -0.633 & 17.1 & -0.595 & $1.605 / 1.990$ & 62.7 \\
\hline $\mathrm{Ni}$ & -0.115 & 20.1 & - & - & - \\
\hline
\end{tabular}




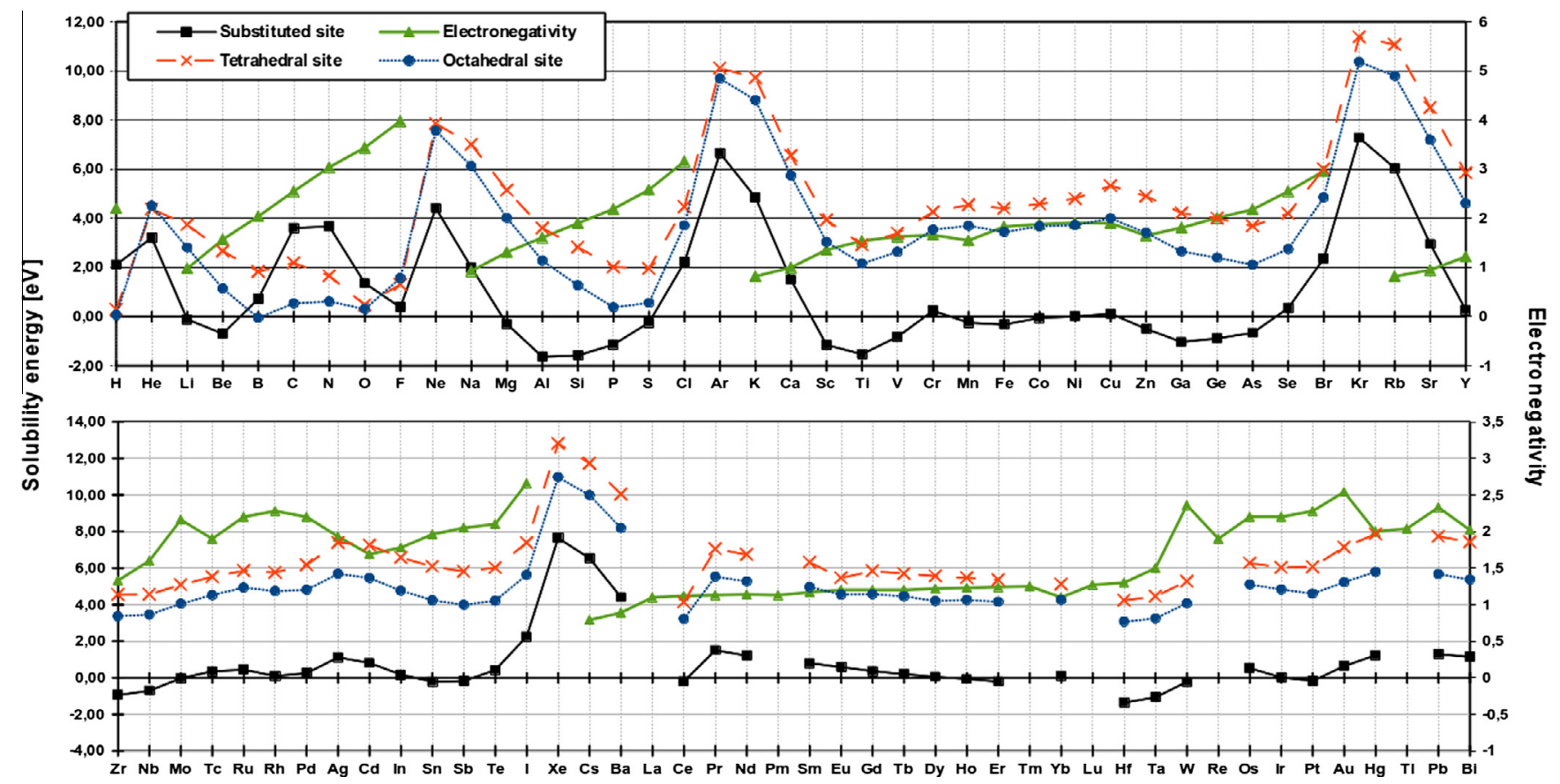

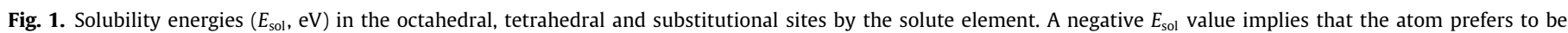
located, at $0 \mathrm{~K}$, in the Ni network rather than in its reference state. We also report the electronegativity.

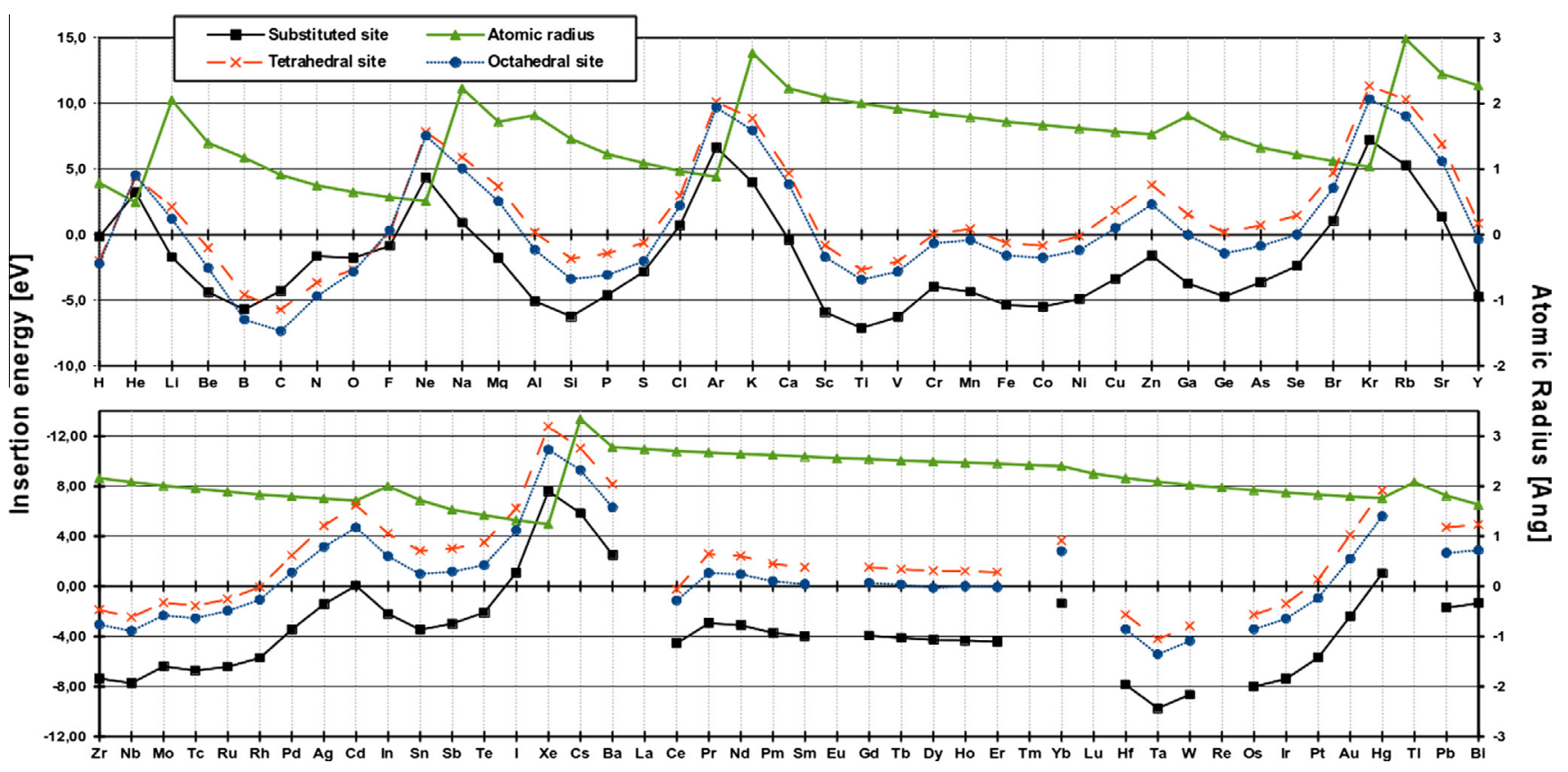

Fig. 2. Insertion energies $\left(E_{\text {ins }}, e V\right)$ in the octahedral, tetrahedral and substitutional sites by the solute element. Atomic radii $(\AA)$ are given (right data).

and the He atom [15]. For the other elements (Ti-Cu line, see [6], for example), only the diffusion mechanisms were discussed.

The insertion energy in the substitutional sites is negative except for some elements: the alkali metals ( $\mathrm{Na}, \mathrm{K}, \mathrm{Rb}, \mathrm{Sr}, \mathrm{Cs}$ and $\mathrm{Ba}$, except $\mathrm{Ca})$, the halogens $(\mathrm{Br}, \mathrm{I}$ and $\mathrm{Cl}), \mathrm{Hg}$ and the rare gases ( $\mathrm{He}, \mathrm{Ne}, \mathrm{Ar}, \mathrm{Kr}$ and $\mathrm{Xe}$ ). The solubility energy of these species indicates that they are poorly soluble in nickel, in agreement with experimental findings [36]. From the solubility energies, one deduces that some species are soluble in nickel, in agreement with the binary phase diagrams: $\mathrm{Be}, \mathrm{Mg}, \mathrm{Al}, \mathrm{Si}, \mathrm{P}, \mathrm{Sc}, \mathrm{Ti}, \mathrm{V}, \mathrm{Ga}, \mathrm{Ge}, \mathrm{Se}, \mathrm{Zr}$, $\mathrm{Nb}$, Hf and Ta. The transition metals are slightly soluble $\left(E_{\mathrm{sol}} \approx\right.$ $0 \mathrm{eV}$ ), which can be explained by the strong stability of their reference states. For these substitutional species, the difference in energy between the substitutional and the interstitial sites is large, up to $2 \mathrm{eV}$. The fraction of atoms $(f)$ in the octahedral

Table 4

$\Delta \epsilon$ is the relative energy between the (O) and (S) sites and $\Delta \epsilon_{b 1}$ is the formation energy of the Vac-X defect. Energies are in eV; $u, K$ and $f$ were computed at $1400 \mathrm{~K}$.

\begin{tabular}{lllllll}
\hline $\mathrm{X}$ & $\Delta \epsilon[X]$ & $u[X]$ & $E^{\text {sol }}[\mathrm{Vac}-X]$ & $\Delta \epsilon_{b 1}[X]$ & $K[X]$ & $f[X]$ \\
\hline $\mathrm{He}$ & 1.18 & 17,700 & 4.37 & -1.16 & $7.10^{-5}$ & $6.10^{-5}$ \\
$\mathrm{~B}$ & -0.69 & $3.10^{-3}$ & -4.53 & -1.17 & $6.10^{-5}$ & 0.997 \\
\hline
\end{tabular}


Table 5

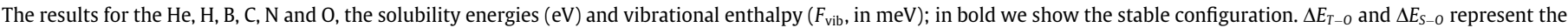

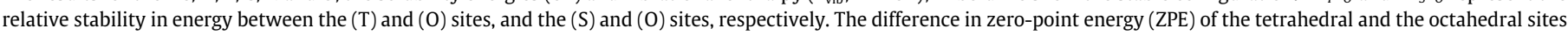
is also given $\left(\triangle \mathrm{ZPE} E_{T-0}\right.$, in $\left.\mathrm{meV}\right)$. We also report the $\mathrm{ZPE}(\mathrm{meV})$ of the reference states (calculated at $\left.0{ }^{\circ} \mathrm{K}\right)$ used to compute $F_{\text {vib }}$.

\begin{tabular}{|c|c|c|c|c|c|c|c|c|c|c|c|}
\hline & \multirow[t]{2}{*}{ (S) } & \multicolumn{3}{|l|}{$(\mathrm{T})$} & \multicolumn{3}{|l|}{$(0)$} & \multirow[t]{2}{*}{$\Delta E_{T-O}$} & \multirow[t]{2}{*}{$\Delta E_{S-O}$} & \multirow[t]{2}{*}{$\triangle \mathrm{ZP} E_{T-O}$} & \multirow[t]{2}{*}{ ZPE[ref] } \\
\hline & & $E_{\mathrm{sol}}$ & ZPE & $F_{\mathrm{vib}}$ & $E_{\text {sol }}$ & ZPE & $F_{\text {vib }}$ & & & & \\
\hline $\mathrm{He}$ & 3.21 & 4.393 & +72 & +72 & 4.556 & +46 & +46 & -0.16 & -1.35 & +26 & 0 \\
\hline $\mathrm{H}$ & 2.11 & 0.290 & 239 & +105 & 0.061 & 150 & +16 & 0.23 & 2.05 & +89 & $134^{\mathrm{a}}$ \\
\hline B & 0.66 & 1.817 & 104 & -22 & 0.033 & 116 & -11 & 1.78 & 0.63 & -12 & $126^{\mathrm{b}}$ \\
\hline$C$ & 3.61 & 2.186 & 118 & -60 & 0.540 & 115 & -63 & 1.65 & 3.07 & -3 & $178^{\mathrm{c}}$ \\
\hline $\mathrm{N}$ & 3.68 & 1.662 & 120 & +45 & 0.617 & 102 & +27 & 1.05 & 3.06 & +16 & $75^{\mathrm{d}}$ \\
\hline 0 & 1.36 & 0.474 & 103 & +58 & 0.311 & 78 & +33 & 0.16 & 1.05 & +25 & $45^{\mathrm{e}}$ \\
\hline
\end{tabular}

a ZPE on the $\mathrm{H}_{2}$ molecule $\left(\omega=4351 \mathrm{~cm}^{-1}\right)$.

b ZPE on the rhombohedric structure [25], approximated in $\Gamma$.

c DFTP calculation [41].

d ZPE on the $\mathrm{N}_{2}$ molecule $\left(\omega=2419 \mathrm{~cm}^{-1}\right)$.

e ZPE on the $\mathrm{O}_{2}$ molecule $\left(\omega=1597 \mathrm{~cm}^{-1}\right)$.

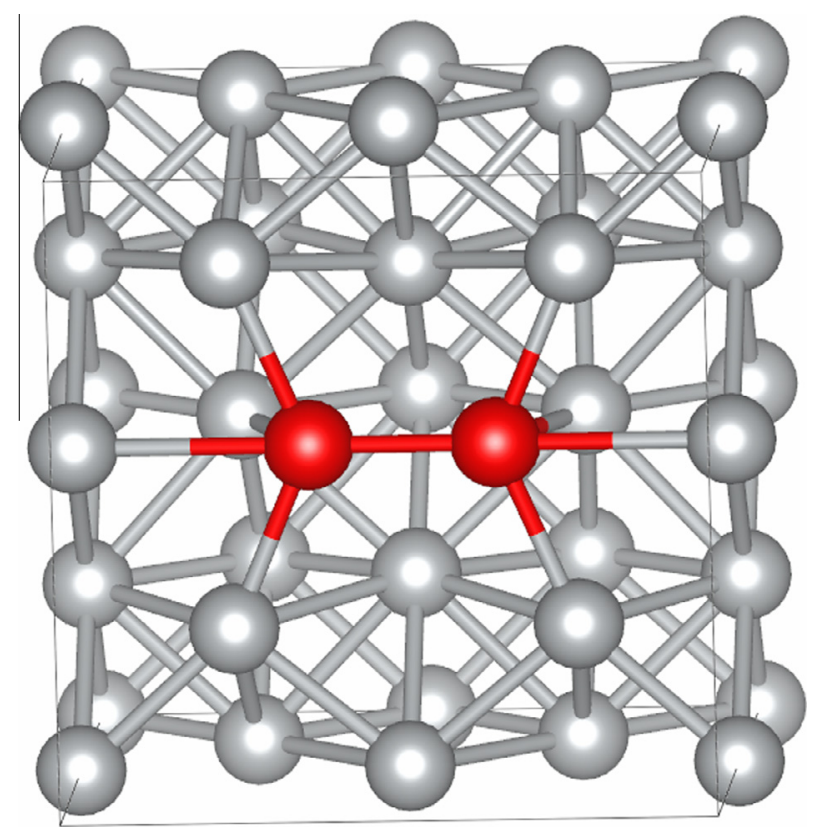

Fig. 3. Schematic of the dumbbell (in red) inside a nickel supercell. (For interpretation of the references to colour in this figure legend, the reader is referred to the web version of this article.)

(or tetrahedral) sites according to the substitutional sites provided to first order can be calculated by

$f=N_{\text {octa }}[X] / N_{\text {sub }}[X] \propto \exp \left(-\Delta \epsilon[X] / k_{B} T\right)$,

where $\Delta \epsilon[X]$ is equal to $E_{\text {octa }}^{\text {sol }}[X]-E_{\text {sub }}^{\text {sol }}[X]$. The fraction of atoms in interstitial sites is then negligible, even at high temperature (because $\Delta \epsilon[X]$ is always greater than $1 \mathrm{eV}$ ). The solute occupies only the substitutional sites.

It can be fruitful to correlate these results with Hume-Rothery's rules [37]. To have a high solubility, four criteria have been proposed: (i) the atomic radii of the solute and the Ni atom must differ by no more than $15 \%$ (Fig. 2); (ii) the crystal structures of solute and solvent must match; (iii) a metal with a lower valency is more likely to dissolve in one with a higher valency; (iv) the solute and solvent should have similar electronegativity. If the electronegativity difference is too great, the metals will tend to form intermetallic compounds instead of solid solutions. We note that for the transition metals, the criteria agree with our results. However, in the case of the $p$-shell elements (groups $13-16$ of the periodic table), the radius and the electronegativity differ from those of nickel, yet they are readily soluble in nickel. For nickel, these criteria can not be relied upon. We can not give a general trend that relies on the solubility energies, the electronegativity and the radius of the species in solid solution.

For the $\mathrm{S}$ and $\mathrm{Nb}$ atoms, our results agree with the theoretical literature $[13,14,8]$. One obtains $\approx-0.24$ and $-0.71 \mathrm{eV}$ for the solubility energies, respectively.

The case of $\mathrm{He}$ is particularly striking. Its stable position remains unclear in the literature. Its size $(\approx 0.30 \AA)$ suggests that its preferred position is the interstitial site. Moreover, experimentally, Philipps, et al. $[38,39]$ ascribed the low activation energy of the He atom $(\approx 0.14 \mathrm{eV})$ to an interstitial mechanism, hindered by trapping at vacancies. However, as noted by Adams [15], He atoms should be located in the substitutional sites. The embedded-atom-method (EAM) value (1.51 eV [15]) is much lower than the DFT value (3.21 eV), but the trend is the same: He atoms should be located in the substitutional sites. The tetrahedral site is $1.18 \mathrm{eV}$ higher than the substitutional site, but lower in energy than the octahedral site. This result is thus slightly different from the results obtained by Adams. We evaluated the fraction of He atoms in the tetrahedral sites (labeled $f^{\text {tetra }}[\mathrm{He}]$ ). McLellan [40] proposed a thermodynamic approach to quantify the fraction of atoms in the interstitial sites (for example $f^{\text {tetra }}[X]=N_{\text {tetra }}[X] / N_{\text {tot }}[X]$ ). It is necessary to account for the interactions between the $X$ atom and a nearest neighboring vacancy (labeled "Vac"). The fraction is provided to first-order approximation by

$f^{\text {tetra }}[X] \simeq \frac{1}{1+u[X](1+z K[X])}$

where $z$ is the coordination number (here $z=12$ ), and $u[X]$ is equal to $\exp \left[\Delta \epsilon[X] / k_{B} T\right] . \Delta \epsilon[X]$ is equal to $E_{\text {tetra }}^{\text {sol }}[X]-E_{\text {sub }}^{\text {sol }}[X]$ and the quantity $K[X] \quad$ is provided by: $K[X]=\exp \left[\Delta \epsilon_{b 1}[X] / k_{B} T\right]$ where $\Delta \epsilon_{b 1}[X]=E_{\text {sub }}^{\text {sol }}[X]-E^{\text {sol }}[$ Vac $-X]$. The $E^{\text {sol }}[$ Vac $-X]$ value is the solubility energy of the Vac- $X$ defect, where the vacancy is in a first nearest-neighbor atomic position of the solute X. In Table 4, we list all the values. $f[\mathrm{He}]$ corresponds to the He fraction in the tetrahedral sites, which is approximately $10^{-5}$ at $1400^{\circ} \mathrm{K}$; thus He atoms are located only in the substitutional sites. We can now interpret the experimental findings of Philipps et al. [38]. The binding energy of He atoms in substitution is also equal to $E^{b}=\Delta \epsilon+E_{1 v}^{f}=2.55 \mathrm{eV}$. Moreover, as we will see in the last section, because the migration energy of the He atom is low, the dissociation energy $\left(E^{b}+E^{m}\right)$ is in excellent agreement with the experimental value, $\approx 2.4 \mathrm{eV}$ [38]. The $\mathrm{He}$ atom is thus in substitution and diffuses through interstitial sites. 


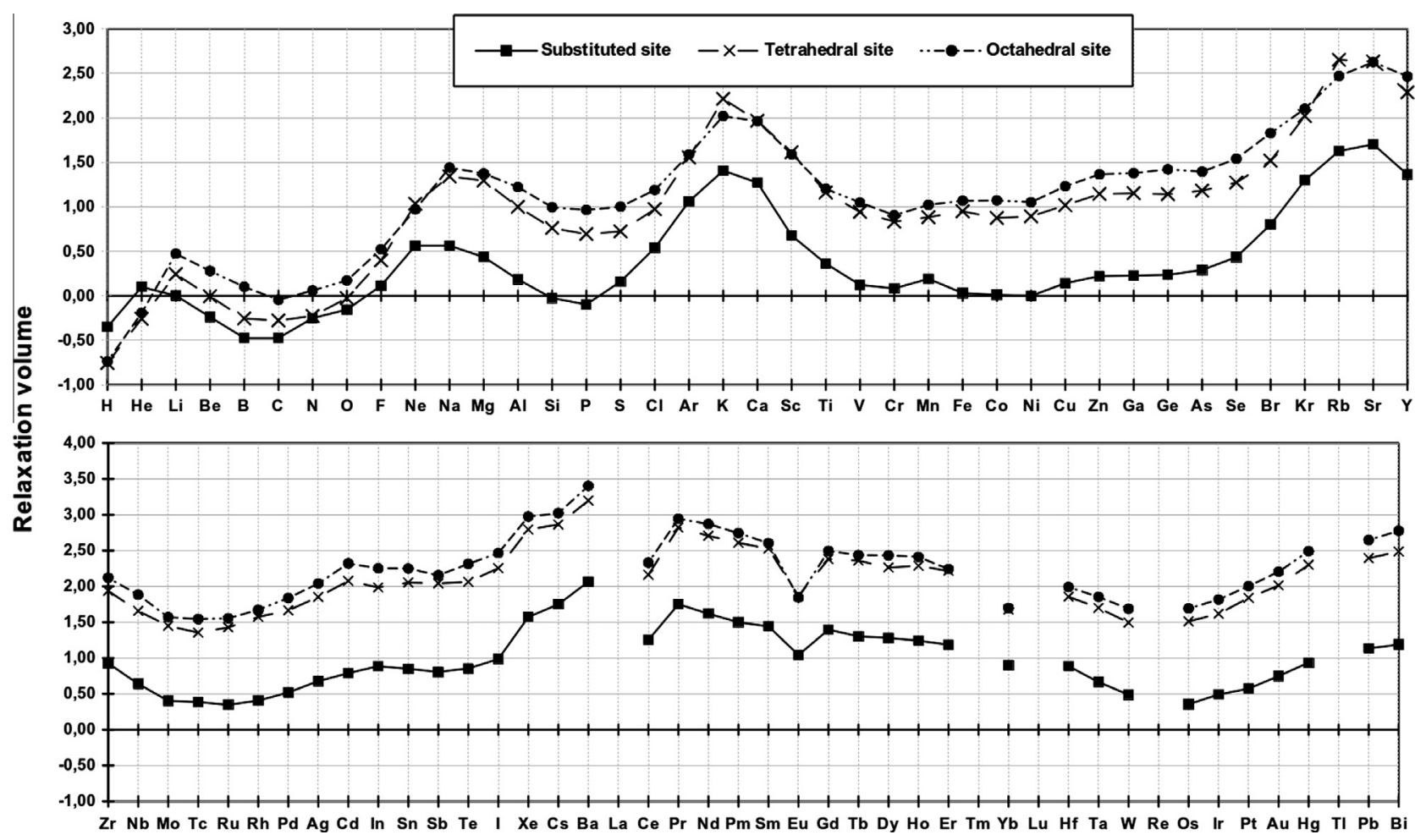

Fig. 4. Relative evolution of the relaxation volume $\left(\Delta V / V_{a t}\right.$, in \%, calculated on a $2 \times 2 \times 2$ supercells) with substitution and insertion.

\subsection{Interstitial species}

Unlike the results obtained for most of the elements, carbon, oxygen, hydrogen, nitrogen and boron prefer to be located in the octahedral sites. These solutes are smaller than the interstitial sites in the solvent lattice, here 0.51 and $0.28 \AA$ (in agreement with the first Hume-Rothery rule). Their solubility energies are low (Fig. 1) but almost all positive (Table 5), and these elements are sparingly soluble in nickel. In addition, we give in the Table 5 the vibration correction (including the zero-point energy of the reference states). We note that the correction is always small in comparison to the solubility energy except for the $\mathrm{H}$ atom. In the case of $\mathrm{C}$ [9], $\mathrm{O}$ [11] and $\mathrm{H}$ [12], our results agree with the experimental and theo-

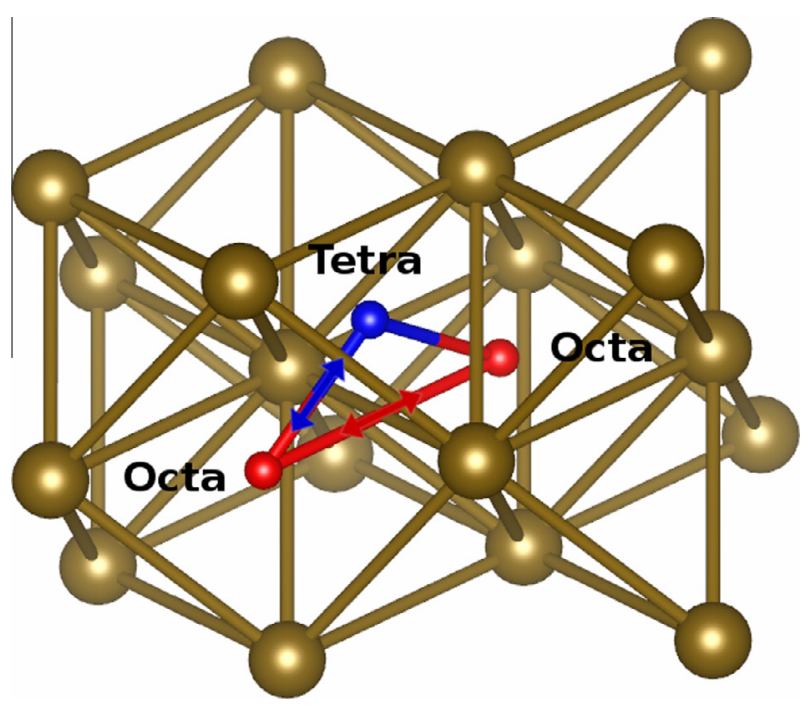

Fig. 5. Migration pathways: $(\mathrm{O}-\mathrm{O})$ and $(\mathrm{O}-\mathrm{T})$ sites. retical literature. The $\mathrm{C}, \mathrm{O}$ and $\mathrm{H}$ atoms are poorly soluble in nickel. For the $\mathrm{B}$ and $\mathrm{N}$ atoms, no value is available. However, the binary phase diagrams suggest that $\mathrm{B}$ atoms are soluble, unlike $\mathrm{N}$ atoms, in agreement with our results. For $\mathrm{H}$ and $\mathrm{O}$ atoms, the difference in energies between the tetrahedral and octahedral site is low $(\Delta \mathrm{E}[(\mathrm{T})-(\mathrm{O})]$ in Table 5$), \approx 0.2 \mathrm{eV}$. These results suggest that, for these interstitial elements, the migration process could occur preferentially through the tetrahedral site (the shortest distance). On the contrary, for the $\mathrm{N}, \mathrm{C}$ and $\mathrm{B}, \Delta \mathrm{E}[(\mathrm{T})-(\mathrm{O})]$ is large, up to $1 \mathrm{eV}$. The migration mechanism is therefore more complex, involving both sites, i.e., tetrahedral-octahedral (TO) and octahedral-octahedral (OO) migration paths (see Section 4).

In the case of the $B$ atom, we find that the substitutional site is significantly more stable than the tetrahedral site by $\approx 0.8 \mathrm{eV}$. The $B$ atoms are thus located in the octahedral sites, but may diffuse through a hybrid mechanism, implicating the substitutional sites. As for $\mathrm{He}$, we evaluated the fraction of the B atoms in the octahedral sites (Table 4). At low temperature, B atoms should be located in the interstitial site, whereas at high temperature (near the fusion point), the fraction of $B$ atoms in the substitutional sites became less negligible $\left(1-f \approx 3 \cdot 10^{-3}\right)$. This result could bear strongly on the interpretation of its diffusivity at high temperature. Its diffusion could be hindered by thermal vacancies, as for the $\mathrm{He}$ atoms.

\subsection{The intrinsic defects}

We now discuss the two main intrinsic defects that can be found in nickel, the dumbbell and the vacancies (mono- and divacancies).

The dumbbell can be shown as an intermediate defect between the interstitial site (i.e., the octahedral site) and the vacancy. In the fcc systems, a Ni atom in an octahedral site is pushed toward one of its nearest neighboring $\mathrm{Ni}$ atoms, thus slightly displaced from its ideal position. In Fig. 3, we represent the schematic of the 

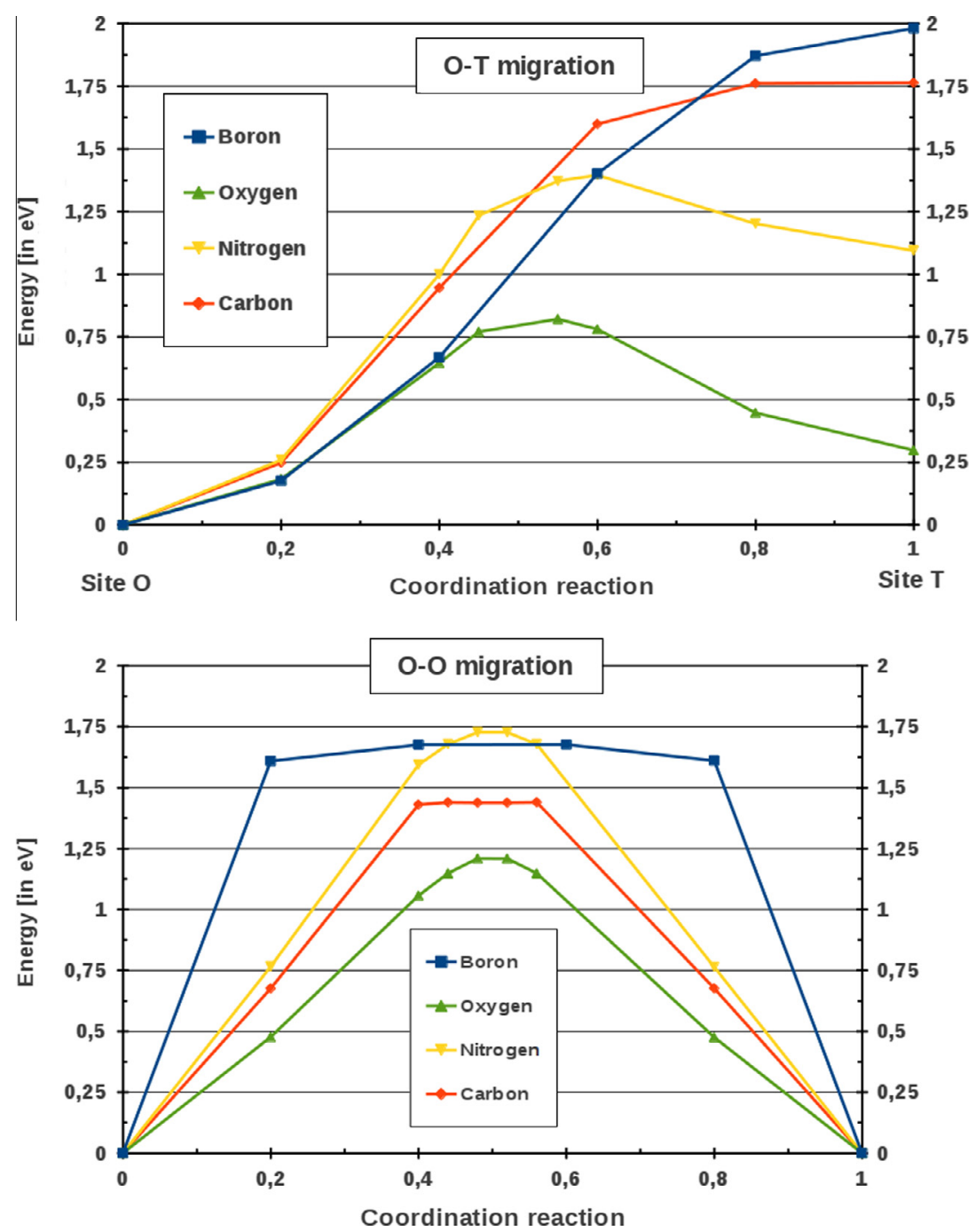

Fig. 6. Schematic of the migration mechanism paths: NEB results for the (TO) and (OO) paths energies, obtained on $2 \times 2 \times 2$ surpercells.

Table 6

Migration energies $\left(E^{m}\right.$, in $\left.\mathrm{eV}\right)$ for $\mathrm{He}, \mathrm{B}, \mathrm{C}, \mathrm{H}, \mathrm{N}$ and $\mathrm{O}$ atoms and the $\delta E$ difference energy between the $(\mathrm{T})$ and $(\mathrm{O})$ sites.

\begin{tabular}{|c|c|c|c|c|}
\hline & $\begin{array}{l}E^{m} \\
(\mathrm{~T} \rightarrow \mathrm{O})\end{array}$ & $\begin{array}{l}E^{m} \\
(\mathrm{O} \rightarrow \mathrm{T})\end{array}$ & $\begin{array}{l}E^{m} \\
(\mathrm{O} \leftrightarrow \mathrm{O})\end{array}$ & $\delta \mathrm{E}[(\mathrm{T})-(\mathrm{O})]$ \\
\hline $\mathrm{He}$ & $0.17^{\mathrm{d}}$ & $0^{\mathrm{d}}$ & $0.02^{b} / 0.03^{d}$ & 0.17 \\
\hline $\mathrm{H}$ & $0.17^{\mathrm{c}} / 0.16^{\mathrm{e}}$ & $0.40^{\mathrm{c}} / 0.40^{\mathrm{e}}$ & $\begin{array}{l}0.69^{\mathrm{c}} / 0.72^{\mathrm{b}} \\
0.85^{\mathrm{e}}\end{array}$ & 0.23 \\
\hline B & $0^{c, d}$ & $1.78^{d} / 1.78^{c}$ & $\begin{array}{l}1.26^{\mathrm{a}} / 1.32^{\mathrm{b}} \\
1.67^{\mathrm{c}} / 1.41^{\mathrm{d}}\end{array}$ & 1.78 \\
\hline C & $<0.01^{\mathrm{c}}$ & $1.67^{c} / 1.65^{d}$ & $\begin{array}{l}1.56^{\mathrm{b}} / 1.43^{\mathrm{c}} \\
1.75^{\mathrm{e}} / 1.66^{\mathrm{d}}\end{array}$ & 1.65 \\
\hline $\mathrm{N}$ & $0.30^{c} / 0.28^{d}$ & $1.39^{\mathrm{c}} / 1.31^{\mathrm{d}}$ & $\begin{array}{l}1.30^{\mathrm{a}} / 1.55^{\mathrm{b}} \\
1.72^{\mathrm{c}} / 1.61^{\mathrm{d}}\end{array}$ & 1.05 \\
\hline $\mathrm{O}$ & $0.52^{\mathrm{c}} / 0.53^{\mathrm{d}}$ & $0.82^{\mathrm{c}} / 0.70^{\mathrm{d}}$ & $\begin{array}{l}0.87^{\mathrm{a}} / 0.97^{\mathrm{b}} \\
1.21^{\mathrm{c}} / 1.05^{\mathrm{d}}\end{array}$ & 0.16 \\
\hline
\end{tabular}

a Direct calculation: $2 \times 2 \times 2$ supercell.

b Direct calculation: $3 \times 3 \times 3$ supercell.

c NEB calculations: $2 \times 2 \times 2$ supercell.

d NEB calculations: $3 \times 3 \times 3$ supercell.

e PAW, GGA Ref. [12].

optimized structure of the dumbbell. The $\mathrm{Ni}-\mathrm{Ni}$ distance in the dumbbell $(2.05 \AA)$ is slightly smaller than the inter-atomic distance in fcc $\mathrm{Ni}(2.49 \AA)$. The distance between this dipole and the first $\mathrm{Ni}$ atom is equal to approximately $2.58 \AA$. The added atom is then
Table 7

Migration energies $\left(E^{m}\right.$, in $\left.\mathrm{eV}\right)$ for $\mathrm{B}, \mathrm{C}, \mathrm{H}, \mathrm{N}$ and $\mathrm{O}$ atoms, frequencies $(\omega$, in meV). IS corresponds to the initial state, FS to the final state and TS to the transition state. "nsp" means "not a saddle point".

\begin{tabular}{llllll}
\hline Element & & $\omega(\mathrm{IS})$ & $E^{m}$ & $\omega(\mathrm{TS})$ & $\omega(\mathrm{FS})$ \\
\hline $\mathrm{H}$ & $(\mathrm{OO})$ & $100^{*} 3$ & 0.85 & $\mathrm{nsp}$ & - \\
& $(\mathrm{TO})$ & $159^{*} 3$ & $0.16 / 0.40$ & $128^{*} 2$ & $100^{*} 3$ \\
$\mathrm{~B}$ & $(\mathrm{OO})$ & $77^{* 3}$ & $1.41(\mathrm{M})$ & 118,45 & - \\
& $(\mathrm{TO})$ & $69 * 3$ & $0.0 / 1.78$ & - & $77^{*} 3$ \\
$\mathrm{C}$ & $(\mathrm{OO})$ & $76^{*} 3$ & $1.66(\mathrm{M})$ & 123,25 & - \\
& $(\mathrm{TO})$ & $78^{*} 3$ & $0.0 / 1.65$ & - & $76^{*} 3$ \\
$\mathrm{~N}$ & $(\mathrm{OO})$ & $68^{*} 3$ & 1.60 & $\mathrm{nsp}$ & - \\
& $(\mathrm{TO})$ & $80^{*} 3$ & $0.28 / 1.31$ & $82^{*} 2$ & $68^{* 3}$ \\
$\mathrm{O}$ & $(\mathrm{OO})$ & $52^{*} 3$ & 1.05 & $\mathrm{nsp}$ & - \\
& $(\mathrm{TO})$ & $69 * 3$ & $0.53 / 0.70$ & $71^{*} 2$ & $52^{*} 3$ \\
\hline
\end{tabular}

located near the octahedral site at $0.8 \AA$, which is $1.0 \AA$ from the ideal position. Its formation energy (which is equivalent to $E_{\text {sol }}$ ) is $\approx$ equal to $+3.96 \mathrm{eV}$, in comparison to the solubility energy of one $\mathrm{Ni}$ atom in an octahedral site $(+4.11 \mathrm{eV}$, Table 3$)$. The dumbbell is more stable than in the $(0)$ site, by $\approx 0.15 \mathrm{eV}$. The elastic relaxation around the $\mathrm{Ni}$ atoms permits this decrease of the energy of the dumbbell. 
We can now compare this energy to the formation energy of the main vacancies (mono-vacancy and divacancy) in nickel. We found for the mono-vacancy a value $\approx 1.39 \mathrm{eV}$ (with a $2 \times 2 \times 2$ supercell) and $1.37 \mathrm{eV}$ (with a $3 \times 3 \times 3$ supercell), in agreement with the theoretical literature [8], and smaller than the experimental value $(\approx 1.70 \mathrm{eV}[42,43])$, and the values calculated with corrections [44]. The dumbbell is thus energetically less favored than the vacancy, even at high temperature. In the case of the divacancy, we considered two configurations, i.e., when the two mono-vacancies are located either in the nearest neighbor position $(1 \mathrm{NN})$ or in the next-nearest neighboring position ( $2 \mathrm{NN})$. The formation energy is equal to approximately 2.74 and $2.84 \mathrm{eV}$, respectively. The selfinterstitial defect is thus always higher in energy than the small clusters.

\subsection{Effects of elements on the lattice parameter}

We evaluated the relaxation volume when the defect (vacancies and dumbbell) or the solute is introduced in a perfect fcc crystal. For the self-interstitial defect, the formation volume $\left(V_{\text {for }}\right)$ is provided by:

$V_{\text {for }}^{\text {dum }}=\frac{V[(n+1) \cdot \mathrm{Ni}]-(n+1) \cdot V_{\mathrm{at}}[\mathrm{Ni}]}{V_{\mathrm{at}}[\mathrm{Ni}]}$

where $V_{\text {at }}[\mathrm{Ni}]$ is the atomic volume of $\mathrm{Ni}$ atoms provided by $V[n \cdot \mathrm{Ni}] / n$. For the mono-vacancy, we have:

$V_{\mathrm{for}}^{\mathrm{vac}}=\frac{V[(n-1) \cdot \mathrm{Ni}]-(n-1) \cdot V_{\mathrm{at}}[\mathrm{Ni}]}{V_{\mathrm{at}}[\mathrm{Ni}]}$

$V_{\text {for }}^{\mathrm{vac}}=0.70$, i.e., a relaxation volume $\left(V_{\mathrm{rlx}}^{\mathrm{vac}}\right)$ of -0.30 at.vol, defined by $V_{\mathrm{rlx}}^{\mathrm{vac}}=V_{\text {for }}^{\mathrm{vac}}-V_{\mathrm{at}}[\mathrm{Ni}]$. This value agrees with the experimental $(0.8)$ and theoretical values $(0.7,[45])$. In the case of the dumbbell, we obtain 1.90 for the volume of relaxation $\left(V_{\mathrm{rlx}}^{\mathrm{dum}}=V_{\mathrm{for}}^{\mathrm{dum}}+V_{\mathrm{at}}[\mathrm{Ni}]\right)$. This value depends strongly on the metal: for $\mathrm{Al}$, it has been evaluated to be $\approx 1.9$, and 1.3 for copper [46]. We also analyzed the anisotropy on the lattice parameters induced by the dumbbell, to be low, $\approx 1 \%$.

As for the intrinsic defects, we computed the relaxation volume for each species in the $(\mathrm{S}),(\mathrm{T})$ and $(\mathrm{O})$ sites $\left(V_{\text {rel }}[X]\right)$. To a first-order approximation, the $V_{\text {for }}[X]$ values of the substitutional site were approximated by:

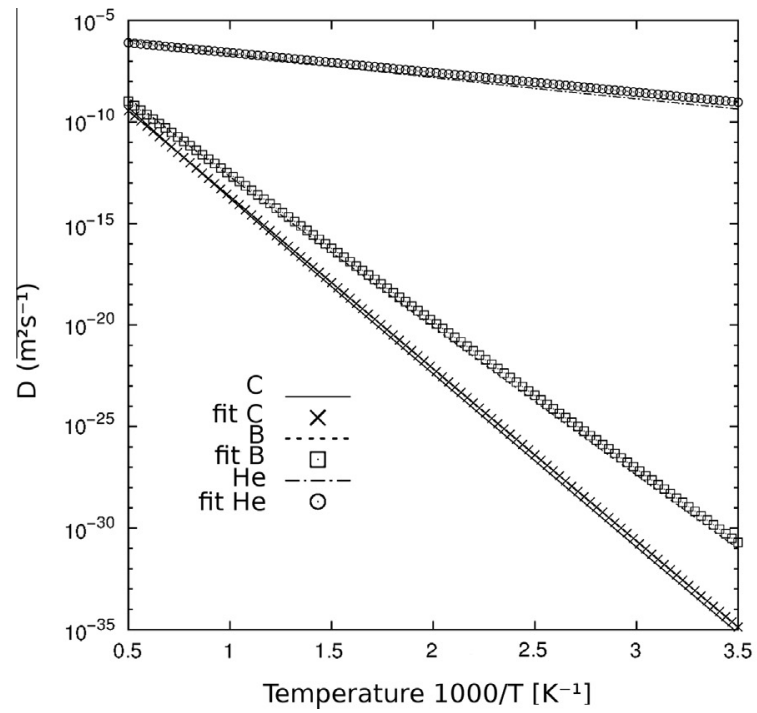

Table A.8

Different energies (in $\mathrm{eV}$ ) used to compute the activation energy (in $\mathrm{eV}$ ) and the prefactor $D_{o}\left(10^{-6} \mathrm{~ms}^{-1}\right)$.

\begin{tabular}{llllll}
\hline & $\Delta G_{s p-o}$ & $\Delta G_{t o}$ & & $E_{a}$ & $D_{o}$ \\
\hline $\mathrm{H}$ & $0.40(-0.022)$ & 0.32 & & 0.41 & 1.31 \\
$\mathrm{~N}$ & $1.31(-0.020)$ & 1.07 & & 1.33 & 1.77 \\
$\mathrm{O}$ & $0.70(-0.007)$ & 0.18 & & 0.71 & 1.15 \\
& $E_{o o}^{m}$ & $E_{o t}^{m}$ & $E_{t o}^{m}$ & $E_{a}$ & $D_{o}$ \\
\hline $\mathrm{He}$ & 0.03 & 0 & 0.16 & 0.19 & 2.5 \\
$\mathrm{~B}$ & $1.41(-0.03)$ & 1.77 & 0 & 1.44 & 4.5 \\
$\mathrm{C}$ & $1.66(-0.04)$ & 1.65 & 0 & 1.68 & 6.3 \\
\hline
\end{tabular}

$V_{\mathrm{for}}[X] \simeq \frac{V[(n-1) \cdot \mathrm{Ni}+X]-n \cdot V_{\mathrm{at}}[\mathrm{Ni}]}{V_{\mathrm{at}}[\mathrm{Ni}]}$

We computed the relaxation volumes of the interstitial sites, using equivalent equations. Fig. 4 shows the relative evolution of the relaxation volume when we insert or substitute an element in the network. These data were obtained on $2 \times 2 \times 2$ supercells. Substitution induces lower steric effects than insertion. The "stable" position of impurities in the network is mainly related to the steric effects. The "free" radii are equal to approximately 0.51 and $0.28 \AA$ in the octahedral and the tetrahedral sites, respectively, whereas in the substitutional site, the radius is $\approx 1.24 \AA$. The substitution induces a contraction of the unit-cell for $\mathrm{B}, \mathrm{Be}, \mathrm{C}, \mathrm{H}, \mathrm{N}, \mathrm{O}$ and P atoms.

\section{Migration processes of elements in interstitial positions}

We now present the diffusion processes of the interstitial species using nudged-elastic band (NEB) calculations [47-49] at constant volume and direct calculations. The simulations were performed on $2 \times 2 \times 2$ and $3 \times 3 \times 3$ supercells to reduce the effects of the relaxation of the box. We considered two migrations processes: along the $(\mathrm{O}-\mathrm{O})$ path, from an octahedral site to the nearest octahedral site, and the ( $\mathrm{T}-\mathrm{O})$ path, from a tetrahedral site to the nearest octahedral site and vice versa (Fig. 5). In the case of (O-O) migration, we also performed direct calculations (on $2 \times 2 \times 2$ and $3 \times 3 \times 3$ supercells), for comparison. The interstitial atom is thus placed in the transition state that is located in the center of the migration process. The choice of this saddle point is confirmed by the NEB simulations (Fig. 6). The results are shown in Table 6.

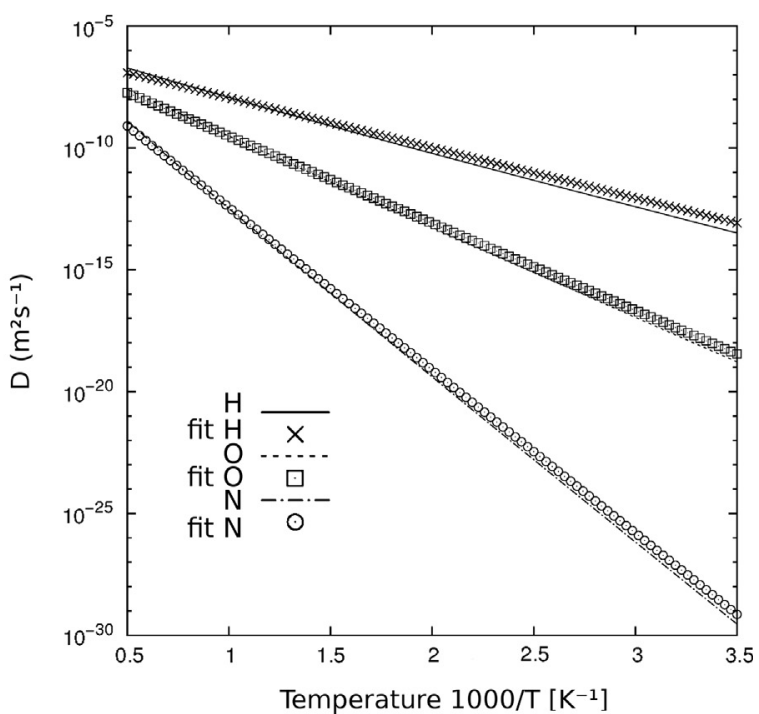

Fig. 7. Computed diffusion coefficient of $\mathrm{H}, \mathrm{He}, \mathrm{C}, \mathrm{N}, \mathrm{B}$ and $\mathrm{O}$ atoms in nickel. We also represent the fits. 
Table B.9

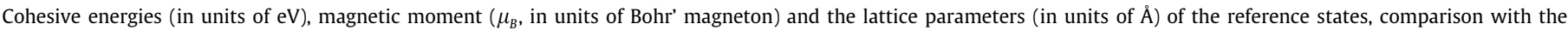
experimental data: Theo./Exp. (if not specified, from Kittel [23]).

\begin{tabular}{|c|c|c|c|c|c|c|c|c|}
\hline Element & Phase & $-\mu_{\mathrm{ref}}^{0}$ & $-E_{\mathrm{coh}}$ & $\mu_{B}$ & $a_{\mathrm{o}}$ & $b_{\mathrm{o}}$ & $c_{\mathrm{o}}$ & $\beta\left({ }^{\circ}\right)$ \\
\hline $\mathrm{Al}$ & fcc & 3.697 & $3.433 / 3.390$ & 0.00 & $4.05 / 4.05$ & & & \\
\hline $\mathrm{Ar}$ & atom & 0.024 & $0.000 / 0.080$ & - & $-/ 5.31$ & & & \\
\hline As [24] & rhombo & 4.574 & $2.980 / 2.960$ & 0.00 & $3.87 / 3.76$ & & $9.46 / 10.55$ & \\
\hline $\mathrm{Au}$ & fcc & 3.202 & $3.044 / 3.810$ & 0.00 & $4.18 / 4.08$ & & & \\
\hline B [25] & rhombo & 6.688 & $6.427 / 5.810$ & 0.00 & $5.05 / 5.06$ & & & $58.0 / 58.0$ \\
\hline $\mathrm{Ba}$ & $\mathrm{cc}$ & 1.923 & $1.894 / 1.900$ & -0.01 & $4.97 / 5.02$ & & & \\
\hline $\mathrm{Be}[26]$ & hcp & 3.729 & $3.689 / 3.320$ & 0.00 & $2.26 / 2.29$ & & $3.56 / 3.58$ & \\
\hline $\mathrm{Bi}$ & $\mathrm{cc}$ & 3.726 & $2.494 / 2.180$ & 0.00 & 3.98 & & & \\
\hline $\mathrm{Br}$ & diatom & 1.496 & $1.301 / 1.220$ & 0.09 & $2.31 / 2.28$ & & & \\
\hline C & diam & 9.100 & $7.894 / 7.370$ & 0.00 & $3.58 / 3.57$ & & & \\
\hline $\mathrm{Ca}$ & fcc & 1.908 & $1.897 / 1.840$ & 0.00 & $5.54 / 5.58$ & & & \\
\hline $\mathrm{Cd}$ & hcp & 0.765 & $0.770 / 1.160$ & 0.00 & $3.19 / 2.98$ & & $5.86 / 5.62$ & \\
\hline $\mathrm{Ce}$ & fcc & 5.964 & $4.364 / 4.320$ & 0.00 & $4.74 / 5.16$ & & & \\
\hline $\mathrm{Cl}$ & diatom & 1.778 & $1.499 / 1.400$ & 0.00 & $2.01 / 1.99$ & & & \\
\hline Co & hcp & 6.990 & $5.435 / 4.390$ & 1.57 & $2.49 / 2.51$ & & $4.02 / 4.07$ & \\
\hline $\mathrm{Cr}$ & $\mathrm{cc}$ & 9.469 & $4.206 / 4.100$ & -0.01 & $2.85 / 2.88$ & & & \\
\hline Cs & $\mathrm{cc}$ & 0.857 & $0.705 / 0.804$ & 0.00 & $6.11 / 6.05$ & & & \\
\hline $\mathrm{Cu}$ & fcc & 3.727 & $3.497 / 3.490$ & 0.00 & $3.64 / 3.61$ & & & \\
\hline Dy & hcp & 4.526 & $4.330 / 3.040$ & 0.00 & $3.60 / 3.59$ & & $5.62 / 5.65$ & \\
\hline $\mathrm{Er}$ & hcp & 4.484 & $4.234 / 3.290$ & 0.00 & $3.57 / 3.56$ & & $5.54 / 5.59$ & \\
\hline $\mathrm{Eu}$ & $\mathrm{cc}$ & 1.862 & $1.869 / 1.860$ & 0.00 & $4.45 / 4.58$ & & & \\
\hline $\mathrm{F}$ & diatom & 1.795 & $1.253 / 0.840$ & - & $1.43 / 1.43$ & & & \\
\hline $\mathrm{Fe}$ & $\mathrm{cc}$ & 8.118 & $5.130 / 4.280$ & 2.15 & $2.83 / 2.87$ & & & \\
\hline Ga [27] & bco & 2.899 & $2.689 / 2.810$ & 0.00 & $4.58 / 4.52$ & $7.73 / 7.66$ & $4.57 / 4.53$ & \\
\hline $\mathrm{Ge}$ & diam & 4.489 & $3.834 / 3.850$ & 0.00 & $5.76 / 5.66$ & & & \\
\hline Gd & hсp & 4.584 & $4.311 / 4.140$ & 0.00 & $3.63 / 3.63$ & & $5.71 / 5.78$ & \\
\hline $\mathrm{H}$ & diatom & 3.401 & $2.280 / 2.260$ & 0.00 & $0.75 / 0.74$ & & & \\
\hline $\mathrm{He}$ & atom & 0.001 & $0.000 /-$ & & & & & \\
\hline $\mathrm{Hf}$ & hcp & 9.833 & $6.500 / 6.440$ & 0.00 & $3.20 / 3.19$ & & $5.05 / 5.05$ & \\
\hline $\mathrm{Hg}$ & rhombo & 0.178 & $0.196 / 0.670$ & 0.00 & $3.15 / 3.01$ & & & $72.2 / 70.5$ \\
\hline Ho & hcp & 4.500 & $4.254 / 3.140$ & 0.00 & $3.59 / 3.58$ & & $5.58 / 5.62$ & \\
\hline I & diatom & 1.327 & $1.170 / 1.110$ & 0.10 & $2.69 / 2.66$ & & & \\
\hline In & $\mathrm{ct}$ & 2.559 & $2.365 / 2.520$ & 0.00 & $3.31 / 3.25$ & & $5.03 / 4.95$ & \\
\hline
\end{tabular}

In the case of the migration between two adjacent octahedral sites, one always obtains symmetric curves, which justifies the direct calculations. However, the direct calculations yield slightly different values in comparison to the NEB calculations on small supercells. The difference $(\approx 0.2-0.3 \mathrm{eV}$, Table 6$)$ can lead to differing conclusions. With large supercells the disagreement is reduced. In the case of the (TO) migration (asymmetric diffusion path) we found that, for two species (boron and carbon), the transition state is located near, or, in the tetrahedral site. Such results have already been mentioned for the $\mathrm{C}$ atoms in fcc-Ni [9] and fcc-Fe [50]. The tetrahedral site for the $\mathrm{B}$ and $\mathrm{C}$ atoms can thus be considered to first-order as the transition state, even if, in the case of $C$ atoms, no imaginary frequencies were found for the tetrahedral configuration. For the $\mathrm{O}$ and $\mathrm{N}$ atoms, the transition state is located at the middle of the path way, in the triangle composed by three $\mathrm{Ni}$ atoms; for the $\mathrm{H}$ atom, it is located near the (T) site as shown by Wimmer [12]. In addition, we calculated the interstitial frequencies for all configurations, i.e., the (T) and (O) sites and those of the transition states. To first-order, only the interstitial frequencies are calculated, neglecting the vibrations of the network (Ni atoms are frozen), and computed using a frozen-mode approach, in which the relative displacements of the interstitial element were equal to 0.01 on $3 \times 3 \times 3$ supercells (harmonic approximation). The results of the simulations are summarized in Table 7.

Our results show two types of migration mechanism. First, H, N and $\mathrm{O}$ atoms diffuse only from the octahedral sites through the tetrahedral sites. We found two imaginary frequencies at the saddle point along the $(\mathrm{OO})$ migration path, meaning that this configuration is not a transition state (labeled "nsp", not a saddle point, in Table 7); the migration is along the (OT) direction. The energy landscapes for these elements are the same as those presented in Fig. 2, Ref. [12]. However, the conclusion is different in the case of the $\mathrm{C}$, He and $\mathrm{B}$ atoms. Both migrations paths are involved in the diffusion mechanism. For the $\mathrm{C}$ and $\mathrm{B}$ atoms, the tetrahedral site can be considered a transition state of the (OT) migration path. We also found that the migration energies are qualitatively equivalent in both paths. In the case of the He atom, the mechanism involves two transition states, between the (OO) and (OT) paths.

We evaluated the coefficient of diffusion using equations given in Appendix A. We also plot the diffusivity (Fig. 7) and and fit activation energies $\left(E_{a}\right)$ and prefactors $\left(D_{0}\right)$, Table A.8. Our values are in excellent agreement with literature for the $\mathrm{H}, \mathrm{O}$ and $\mathrm{C}$ atoms $[12,51,9]$. Specifically, in the case of the He atom, the low activation energy in the interstitial sites is in excellent agreement $(\approx 0.19 \mathrm{eV})$ with the experimental value $(0.14 \pm 0.03 \mathrm{eV}$ [39]), the He atom is in the substituted position but moves through interstitial sites.

\section{Conclusions}

We present a complete database of the solubility and insertion energies of impurities in nickel using first-principles calculations. For most of the elements, the substitutional site is determined to be preferred. As a consequence, their diffusion process can be described by a five-jump-frequencies mechanism [52].

C, O, N, B and $\mathrm{H}$ atoms are the only interstitials elements. Their insertion in the octahedral site is more stable than in the tetrahedral site. The migration energies are calculated for these interstitial elements.

\section{Acknowledgments}

This work was granted access to the HPC resources of CALMIP (CICT Toulouse, France) under the allocation 2012/2013-p0912 
Table B.10

The cohesive energy and the lattice parameters of reference states: comparison with the experimental data: Theo./Exp. (if not specified, from Kittel [23])

\begin{tabular}{|c|c|c|c|c|c|c|c|c|}
\hline Element & Phase & $-E_{o}$ & $-E_{\text {coh }}$ & $\mu_{B}$ & $a_{\mathrm{o}}$ & $b_{\mathrm{o}}$ & $c_{\mathrm{o}}$ & $\beta\left(\left(^{\circ}\right)\right.$ \\
\hline $\mathrm{Ir}$ & fcc & 8.793 & $7.397 / 6.940$ & 0.00 & $3.88 / 3.84$ & & & \\
\hline K & $\mathrm{cc}$ & 1.039 & $0.870 / 0.934$ & 0.00 & $5.27 / 5.59$ & & & \\
\hline $\mathrm{Kr}$ & fcc & 0.069 & $0.050 / 0.116$ & 0.00 & $6.46 / 5.64$ & & & \\
\hline $\mathrm{Li}$ & $\mathrm{cc}$ & 1.898 & $1.620 / 1.630$ & 0.00 & $3.45 / 3.49$ & & & \\
\hline $\mathrm{Mg}$ & hcp & 1.524 & $1.484 / 1.510$ & 0.00 & $3.19 / 3.21$ & & $5.19 / 5.21$ & \\
\hline Mn [28] & $\mathrm{cc}$ & 8.963 & $4.116 /-$ & 0.15 & $8.54 / 8.91$ & & & \\
\hline Mo & $\mathrm{cc}$ & 10.808 & $6.384 / 6.820$ & 0.00 & $3.17 / 3.15$ & & & \\
\hline $\mathrm{N}$ & diatom & 8.337 & $5.318 / 4.920$ & 0.00 & $1.11 / 5.66$ & & & \\
\hline $\mathrm{Na}$ & $\mathrm{cc}$ & 1.304 & $1.098 / 1.113$ & 0.00 & $4.20 / 4.23$ & & & \\
\hline $\mathrm{Nb}$ & $\mathrm{cc}$ & 10.064 & $7.027 / 7.570$ & 0.00 & $3.32 / 3.30$ & & & \\
\hline $\mathrm{Nd}$ & hcp & 4.684 & $4.324 / 3.400$ & 0.00 & $3.70 / 3.66$ & & $5.97 / 5.89$ & \\
\hline $\mathrm{Ne}$ & fcc & 0.057 & $0.046 / 0.020$ & 0.04 & $4.42 / 4.46$ & & & \\
\hline $\mathrm{Ni}$ & fcc & 5.461 & $4.894 / 4.440$ & 0.62 & $3.52 / 3.52$ & & & \\
\hline $\mathrm{O}$ & diatom & 4.891 & $3.135 / 2.600$ & 2.00 & $1.23 / 1.21$ & & & \\
\hline Os & hcp & 11.116 & $8.510 / 8.170$ & 0.00 & $2.76 / 2.74$ & & $4.36 / 4.32$ & \\
\hline P [29] & complex & 5.283 & $3.505 / 3.430$ & 0.00 & $12.44 / 11.45$ & $5.94 / 5.503$ & 12.1811 .26 & $71 ; 89 ; 71 / 71 ; 90 ; 71$ \\
\hline $\mathrm{Pb}$ & fcc & 3.548 & $3.009 / 2.030$ & 0.00 & $5.02 / 4.95$ & & & \\
\hline $\mathrm{Pd}$ & fcc & 5.215 & $3.716 / 3.890$ & 0.29 & $3.96 / 3.89$ & & & \\
\hline Pm & none & -0.022 & $0.000 /-$ & - & $-1-$ & & & \\
\hline $\operatorname{Pr}[30]$ & hcp & 4.725 & $4.465 / 3.70$ & 0.00 & $3.73 / 3.67$ & & $12.10 / 11.84$ & \\
\hline $\mathrm{Pt}$ & fcc & 6.045 & $5.491 / 5.840$ & 0.00 & $3.98 / 3.92$ & & & \\
\hline $\mathrm{Rb}$ & $\mathrm{cc}$ & 0.929 & $0.772 / 0.852$ & 0.00 & $5.70 / 5.59$ & & & \\
\hline Rh & fcc & 7.223 & $5.827 / 5.750$ & 0.00 & $3.85 / 3.80$ & & & \\
\hline $\mathrm{Ru}$ & hcp & 9.160 & $6.887 / 6.740$ & 0.00 & $2.73 / 2.71$ & & $4.30 / 4.28$ & \\
\hline S & diatom & 3.512 & $2.585 / 2.200$ & 2.00 & $1.90 / 1.89$ & & & \\
\hline $\mathrm{Sb}[31]$ & 166 & 4.159 & $2.818 / 2.750$ & 0.00 & $4.38 / 4.31$ & & $11.39 / 11.27$ & \\
\hline $\mathrm{Sc}$ & hcp & 6.225 & $4.751 / 3.900$ & 0.00 & $3.32 / 3.31$ & & $5.15 / 5.27$ & \\
\hline Se [32] & compl & 3.511 & $2.739 / 2.460$ & 0.00 & $4.43 / 4.36$ & & $5.08 / 4.95$ & \\
\hline $\mathrm{Si}$ & diam & 5.432 & $4.655 / 4.630$ & 0.00 & $5.47 / 5.43$ & & & \\
\hline Sn & diam & 3.832 & $3.255 / 3.140$ & 0.00 & $6.64 / 6.49$ & & & \\
\hline Sm [33] & st & 4.638 & $4.794 / 2.140$ & 0.00 & $9.02 / 8.91$ & & & $23.3 / 23.3$ \\
\hline $\mathrm{Sr}$ & fcc & 1.625 & $1.608 / 1.720$ & 0.00 & $6.00 / 6.08$ & & & \\
\hline Та & $\mathrm{cc}$ & 11.735 & $8.676 / 8.100$ & 0.00 & $3.32 / 3.30$ & & & \\
\hline $\mathrm{Tb}$ & hcp & 4.555 & $4.329 / 4.050$ & 0.00 & $3.62 / 3.60$ & & $5.67 / 5.70$ & \\
\hline Tc & hcp & 10.205 & $7.082 / 6.850$ & 0.00 & $2.76 / 2.74$ & & $4.42 / 4.40$ & \\
\hline Te [34] & trigonal & 3.163 & $2.522 / 2.190$ & 0.00 & $4.51 / 4.46$ & & $5.98 / 5.93$ & \\
\hline $\mathrm{Ti}$ & hcp & 7.742 & $5.591 / 4.850$ & 0.00 & $2.92 / 2.95$ & & $4.64 / 4.68$ & \\
\hline V & $\mathrm{cc}$ & 8.926 & $5.448 / 5.310$ & 0.00 & $3.00 / 3.03$ & & & \\
\hline W & $\mathrm{cc}$ & 12.785 & $8.447 / 8.900$ & 0.00 & $3.19 / 3.16$ & & & \\
\hline $\mathrm{Xe}$ & fcc & 0.061 & $0.055 / 0.160$ & 0.00 & $6.99 / 6.13$ & & & \\
\hline Y & hcp & 6.384 & $4.994 / 4.370$ & 0.00 & $3.66 / 3.65$ & & $5.65 / 5.73$ & \\
\hline $\mathrm{Yb}$ & fcc & 1.452 & $1.469 / 1.600$ & 0.00 & $5.39 / 5.48$ & & & \\
\hline $\mathrm{Zn}$ & hcp & 1.113 & $1.116 / 1.350$ & 0.00 & $2.65 / 2.66$ & & $5.01 / 4.95$ & \\
\hline $\mathrm{Zr}$ & hcp & 8.435 & $6.431 / 6.250$ & 0.00 & $3.23 / 3.23$ & & $5.19 / 5.16$ & \\
\hline
\end{tabular}

and 2013-p0842. The authors acknowledge the support of theFrench Agence Nationale de la Recherche (ANR), under Grant EcHyDNA (Blanc 10-19424).

\section{Appendix A. Diffusion mechanisms for interstitial elements}

The temperature-dependent diffusion coefficients of $\mathrm{H}, \mathrm{N}$ and $\mathrm{O}$ interstitials in Ni including equilibration in the metastable (tetrahedral) sites are given by [12]:

$D=a_{o}^{2} \frac{k T}{h} e^{-\Delta G_{s p-o} / k T} \frac{1}{2}\left[1+2 e^{-\Delta G_{t o} / k T}\right]^{-1}$

where $a_{0}$ is the lattice parameter, $\Delta G_{s p-o}=G_{s p}-G_{0}$ is the difference in Gibbs free energy (including the vibrational energy) between the saddle point (sp) and the octahedral site, and $\Delta G_{t o}$ is the difference in the Gibbs free energy of the tetrahedral and octahedral sites. The data are summarized in Table A.8. We also list the activation energies $\left(E_{a}\right)$ and the prefactors $D_{o}$ fitted from an Arrhenius plot. The Arrhenius plot of the computed diffusion coefficient shows a reasonable linear behavior.

In the case of the $\mathrm{C}, \mathrm{He}$ and $\mathrm{B}$ atoms, $D$ depends to the resident time in both sites [53]. The residence time $\left(\tau_{0}\right)$ in the octahedral site is equal to (12 and 8 nearest neighbor octahedral and tetrahedral sites, respectively):

$\tau_{o}^{-1}=\frac{h}{k T}\left(12 \exp \left(-G_{o o}^{m} / k T\right)+8 \exp \left(-G_{o t}^{m} / k T\right)\right)$

$P_{o}=12 \exp \left(-G_{o o}^{m} / k T\right) /\left(12 \exp \left(-G_{o o}^{m} / k T\right)+8 \exp \left(-G_{o t}^{m} / k T\right)\right) \quad$ and $P_{t}=8 \exp \left(-G_{o t}^{m} / k T\right) /\left(12 \exp \left(-G_{o o}^{m} / k T\right)+8 \exp \left(-G_{o t}^{m} / k T\right)\right)$, and in the tetrahedral site (4 nearest neighbor octahedral sites):

$\tau_{t}^{-1}=\frac{h}{k T}\left(4 \exp \left(-G_{t o}^{m} / k T\right)\right)$

The time to move from an octahedral site to an other octahedral site $(\langle\tau\rangle)$ is:

$\langle\tau\rangle=\left[\frac{\tau_{o} P_{o}}{1-P_{t} / 4}+\frac{\left(\tau_{o}+\tau_{t}\right)\left(P_{o}+3\right) P_{t} / 4}{\left(1-P_{t} / 4\right)^{2}}\right]$

the diffusion coefficient is finally equal to:

$D=L^{2} / 6 /\langle\tau\rangle$ where $L^{2}=a_{o}^{2} / 2$

The different energies are listed in Table A.8. 


\section{Appendix B. Reference states}

Tables B.9 and B.10.

\section{References}

[1] G. Sabol, R. Stickler, Physica Status Solidi 39 (1969) 11.

[2] A. Jena, M. Chaturvedi, J. Mater. Sci. 19 (1984) 3121.

[3] D. Connétable, Y. Wang, D. Tanguy, J. Alloys Compd. 614 (2014) 211.

[4] D. Tanguy, Y. Wang, D. Connétable, Acta Materialia (2014). note submitted.

[5] D. Young, High Temperature Oxidation and Corrosion of Metals, Elsevier Corrosion series, 2008.

[6] A. Janotti, M. Fremar, C. Fu, R. Reed, Phys. Rev. Lett 085901 (2004).

[7] M. Yamaguchi, M. Shiga, H. Kaburaki, J. Phys.: Condens. Matter 16 (2004) 3933.

[8] D. Connétable, B. Ter-Ovanessian, E. Andrieu, J. Phys.: Condens. Matter 24 (2012) 095010.

[9] D. Siegel, J. Hamilton, Phys. Rev. B 68 (2003) 094105.

[10] S. Garruchet, O. Politano, P. Arnoux, V. Vignal, Solid State Commun. 150 (2010) 439.

[11] J. Kim, S. Shin, J. Jung, K. Choi, J. Kim, Appl. Phys. Lett. 100 (2012) 131904.

[12] E. Wimmer, W. Wolf, J. Sticht, P. Saxe, C. Geller, R. Najafabadi, G. Young, Phys. Rev. B 77 (2008) 134305.

[13] H. Kart, M. Uludogan, T. Cagin, Computat. Mater. Sci. 44 (2009) 1236.

[14] D. Kandaskalov, D. Monceau, C. Mijoule, D. Connétable, Surface Sci. 617 (2013) 15.

[15] J. Adams, W. Wolfer, J. Nucl. Mat. 158 (1988) 25.

[16] G. Kresse, J. Hafner, Phys. Rev. B 47 (1993) 558.

[17] G. Kresse, J. Hafner, Phys. Rev. B 49 (1994) 14251.

[18] G. Kresse, J. Furthmüller, Phys. Rev. B 54 (1996) 11169.

[19] G. Kresse, J. Furthmüller, Comput. Mater. Sci. 6 (1996) 15.

[20] G. Kresse, D. Joubert, Phys. Rev. B 59 (1996) 1758.

[21] Y. Wang, J.P. Perdew, Phys. Rev. B 44 (1991) 13298

[22] For $n \times n \times n$ supercells, we used 24/n $\times 24 / n \times 24 / n k$-meshes.

[23] C. Kittel, Introduction to Solid State Physics, Wiley, New York, 1996.

[24] D. Schiferl, C.S. Barrett, J. Appl. Crystallogr. 2 (1969) 30.

[25] L.V. McCarty, J.S. Kasper, F.H. Horn, B.F. Decker, A.E. Newkirk, J. Am. Chem. Soc. 80 (1958) 2592.
[26] Y. Yang, P. Coppens, A. Crystallogr. 34A (1978) 61.

[27] B.D. Sharma, J. Donohue, Z. Kristallogr. Kristallgeom. Kristallphys. Kristallchem. 117 (1962) 293.

[28] C. Gazzara, R. Middleton, R. Weiss, E. Hall, Acta Crystallogr. 22 (1967) 859.

[29] A. Simon, H. Borrmann, H. Craubner, Phosphorus Sulfur Related Elements 30 (1987) 507.

[30] F.H. Spedding, A.H. Daane, K.W. Herrmann, Acta Crystallogr. 9 (1956) 559.

[31] D. Schiferl, Rev. Scient. Instrum. 48 (1977) 24.

[32] A. Bradley, Phil. Mag. 48 (1924) 477.

[33] A.H. Daane, R.E. Rundle, H.G. Smith, F.H. Spedding, Acta Crystallogr. 7 (1954) 532.

[34] P. Cherin, P. Unger, Acta Crystallogr. 23 (1967) 670.

[35] H. Monkhorst, J. Pack, Phys. Rev. B 13 (1976) 5188.

[36] A. Strawbridge, R.A. Rapp, J. Electrochem. Soc. 141 (1994) 1905.

[37] W. Hume-Rothery, R.W. Smallman, C.W. Haworth, The Structure of Metals and Alloys, The Institute of Metals, London, 1969.

[38] V. Philipps, K. Sonnenberg, J. Williams, J. Nucl. Mat. 107 (1982) 271.

[39] V. Philipps, K. Sonnenberg, J. Nucl. Mat. 114 (1983) 95.

[40] R. McLellan, J. Phys. Chem. Solids 50 (1989) 49.

[41] D. Connétable, Phys. Rev. B 82 (2010) 075209.

[42] S. Nanao, K. Kuribayashi, S. Tanigawa, M. Doyama, J. Phys. F: Met. Phys. 7 (1977) 1403.

[43] J.L. Campbell, C.W. Schulte, J.A.S. Jackman, J. Phys. F: Met. Phys. 7 (1977) 1985

[44] L. Delczeg, E. Delczeg-Czirjak, B. Johansson, L. Vitos, Phys. Rev. B 80 (2009) 205121.

[45] P. Korzhavyi, I. Abrikosov, B. Johansson, A. Ruban, H. Skriver, Phys. Rev. B 59 (1999) 11693.

[46] W. Schilling, J. Nucl. Mat. 67-70 (1978) 465.

[47] H. Jónsson, G. Mills, K. Jacobsen, Classical and quantum dynamics, in: Condensed Phase Simulations, World Scientific, Singapore, 1998, p. 385.

[48] G. Henkelman, B. Uberuaga, H. Jónsson, J. Chem. Phys. 113 (2000) 9901.

[49] G. Henkelman, H. Jónsson, J. Chem. Phys. 113 (2000) 9978.

[50] D. Jiang, E. Carter, Phys. Rev. B 67 (2003) 214103.

[51] H. Fang, S. Shang, Y. Wang, Z. Liu, D. Alfonso, D. Alman, Y. Shin, C. Zou, A. van Duin, Y. Lei, G. Wang, J. Appl. Phys. 115 (2014) 043501.

[52] A. LeClaire, A. Lidiard, Phil. Mag. 47 (1955) 518.

[53] H. Gunaydin, S.V. Barabash, K.N. Houk, V. Ozolins, Phys. Rev. Lett. 101 (2008) 075901. 